\title{
1 Comparative secretomics identifies conserved WAxR 2 motif-containing effectors in rust fungi that suppress 3 cell death in plants
}

4 Rajdeep Jaswal1,2, Himanshu Dubey², Kanti Kiran², Hukam Rawal2, Sivasubramanian

5 Rajarammohan ${ }^{1}$, Pramod Prasad ${ }^{4}$, Subhash C Bhardwaj ${ }^{4}$, Humira Sonah ${ }^{1}$, Rupesh

6 Deshmukh $^{1}$, Naveen Gupta ${ }^{2}$ and Tilak Raj Sharma ${ }^{1,5^{*}}$

\section{Affiliations:}

$8 \quad{ }^{1}$ National Agri-Food Biotechnology Institute (NABI), Mohali, Punjab, India -140306

92 Department of Microbiology, Panjab University, Chandigarh, Punjab, India - 160014

103 National Institute on Plant Biotechnology, Pusa Campus New Delhi, India - 110012

114 ICAR-Indian Institute of Wheat and Barley Research, Regional Station, Flowerdale,

12 Shimla, India - 171009

135 Indian Council of Agricultural Research, Division of Crop Science, Krishi Bhavan, New

14 Delhi, India, 110001, India

15 Corresponding author

16 Dr. T R Sharma (trsharma1965@gmail.com )

17 Phone: 91-11-23382545

18 Indian Council of Agricultural Research, Division of Crop Science,

19 Krishi Bhavan, New Delhi,110001, India 


\section{Highlights}

- Secretome analysis of various plant pathogens performed

- A prioritization list for candidate effectors designed

- A novel WAxR motif was discovered in rust fungal effector proteins

- Two WAxR candidate effectors were functionally validated

\section{Abstract}

Identification of novel effectors with conserved features has always remained a challenge in plant-pathogen interaction studies. The introduction of the genomics era in plantpathogen studies has led to the identification of significant candidate effectors with novel motifs such as RxLR and dEER motifs. However, in the case of fungal pathogens, limited conserved motifs associated with effectors have been discovered yet. In the present study, we have performed comparative secretome analysis for major plant pathogens of diverse nutrition mechanisms with the aim of dissecting the features underlying their corresponding secretome and conserved motifs. We showed that rust fungi possess the lowest Cell wall degrading enzymes (CWDEs) consortium lower than other biotrophic pathogens. We also showed rust fungi possess the highest secretory superoxide dismutase (SOD) than other studied plant pathogens. Further, we prioritized the candidate secretory effectors proteins (CSEPs) of all the studied pathogens by combining various effector mining parameters to highlight the candidates with potential effector features. A novel WAxR motif in conjugation with the $\mathrm{Y} / \mathrm{F} / \mathrm{WxC}$ (FGC) motif was identified in the effectors of various $P$. striiformis races present globally. The WAxR/WAxR like motifs ( WxxR, WAxx, xAxR) containing effectors were also found in the secretome of other rust fungi. Further, the functional validation of two candidate effectors with WAxR motif from P. strïformis Yrg showed that these effectors localize to 
47 the nucleus as well as cytoplasm, and are able to suppress BAX induced cell death in

48 Nicotiana benthamiana. The mutation analysis of individual residues of the WAxR motif

49 (W, A, R ) however did not affect the cell death suppression nor subcellular localization

50 of these effectors. Overall, the current study reports the presence of novel motifs in large

51 numbers of effectors of rust fungi with cell death suppression features.

52 Keywords: rust fungi, effectors, secretome, motifs, plant pathogens

\section{Introduction}

55

56

57

58

59

60

61

62

The plant pathogens follow different nutrition mechanisms explicitly called saprotrophic, necrotrophic, hemibiotrophic, and biotrophic lifestyles. Despite being associated with a different lifestyle, all these pathogens follow a common mechanism for the establishment of infection i.e secretion of small proteinaceous molecules preferably called effectors as these proteins are primarily involved in the manipulation of the host's defense machinery (Jaswal et al., 2020). To gain entry inside the host cell, these pathogens secrete various cell wall-degrading enzymes (CWDEs) that cause loosening of the cell wall. The successful loosening of the cell wall further causes the transfer of various apoplastic, cytoplasmic effectors as well as virulence determinants that suppress the immunity of the host in numerous ways. Several novel mechanisms have been utilized by pathogens that have been highlighted by recent studies, such as suppressing RNA interference, targeting various cellular organelles of host plants, and maintaining conserved fold in the novel effectors to perform a conserved molecular function(de Guillen et al., 2019; Jaswal et al., 2020; Mukhi et al., 2020; Xu et al., 2019; Yin et al., 2019). 
Next-generation sequencing (NGS) technologies have led to the generation of

71 huge genomics and transcriptomic data for plant pathogens. The bioinformatics tools

72 have also been used successfully to identify secretomic differences of the various plant-

73 fungal pathogen using publically available data(Guyon et al., 2014; Jaswal et al., 2019;

74 Ozketen et al., 2020; Sperschneider et al., 2018). However, very few studies have been

75 able to highlight the conserved effector features such as motif or domain in the

76 candidate effector proteins. Despite the huge availability of NGS data, only a limited

77 number of conserved effectors and motifs have been identified and validated to date.

78 The sequence diversity and absence of common features have been a great hurdle for the

79 identification of conserved effector proteins in fungal pathogens. Additionally, the

80 frequent evolution caused by host resistance ( $R$ ) genes leading to diversification,

81 moreover species-specific role or functional diversity makes these effectors and their

82 corresponding motifs difficult to identify and develop consensus even using

83 bioinformatics tools (Sonah et al., 2016).

Using computational genomics, two major conserved motifs RxLR and dEER present in several effector members of oomycetes have been identified. These RxLR members constituting the largest effector family in plant pathogens till now are responsible for the translocation of effectors proteins in plant cytoplasm (Dou et al., 88 2008; Kale et al., 2010; Wang et al., 2021; Whisson et al., 2007). In addition to this, the WY motif and CRN effectors have also been identified in oomycetes. Few other motifs 90 have also been identified however their presence is limited to selected candidates (Jones 91 et al., 2018). 
In the case of obligate biotrophs, Blumeria graminis, the $\mathrm{N}$ terminal $\mathrm{Y} / \mathrm{F} / \mathrm{WxC}$

93 motif is present in various haustorially expressed secreted proteins (Godfrey et al.,

94 2010). The $\mathrm{Y} / \mathrm{F} / \mathrm{WxC}$ motifs have also been highlighted to be present in haustorially

95 enriched secretory proteins of rust fungi however the exact function of these motifs is

96 yet to be determined(Ozketen et al., 2020; Zhao et al., 2020). In addition to this, a

97 motif sequence [SG]PC[KR]P has been identified in some of the Fusarium secretory

98 proteins, but functional validation of these motifs needs to be done (Ma et al., 2010;

99 Sperschneider et al., 2013). Apart from these, no other conserved motif pattern has been

100 identified in fungal effector proteins using sequence-based studies, especially in rust

101 fungi.

Currently, few universal common features have been explored to mine effector proteins in various studies i) presence of signal peptide, ii) small size $\leq 300$ amino acids and $\geq 3 \%$ cysteine content, iii) nuclear localization signal (NLS), iv) repeat sequences, v) signature of positive selection pressure, vi) presence of conserved motif sequences, vii) no conserved domain or pathogenicity related domain reported in other organisms and viii) high expression at the time of infection. Multiple studies have used these parameters to identify candidate effectors across various pathogens (Duplessis et al., 2011; Mesarich et al., 2015; Xu et al., 2020). Apart from these parameters, recently developed tools like EffectorP and Localizer have become useful for prioritizing the effector candidates from total secretomes (Jaswal et al., 2019; Sperschneider et al., 2017, 112 2016) Although, the common signature features have been frequently explored to 113 identify effector proteins in various pathogens, combining tools like EffectorP and 114 Localizer along with other features can aid in the refinement and better prioritization of 
115 these proteins. The hypothesis that candidates that follow the maximum number of 116 parameters, out of the all the candidates analyzed could be prioritized and can be used 117 to mine potential effectors. In the case of rust fungi, hierarchical clustering has been also 118 implemented to find the consensus among candidate effectors(Saunders et al., 2012). 119 Unfortunately not all the proteins follow the selected parameters but probably can be 120 used to increase the confidence score of selecting the protein as a target. Furthermore, 121 expression analysis using publically available data can be utilized as additional support, 122 to target these proteins as the prime candidates.

In the present study, we have followed a comparative genomics approach to 124 analyze the differences among various plant pathogens with varied lifestyles at the 125 secretome level. We used softwares like effectorP and localizer in addition to previously 126 known benchmarks for effector identification and then prioritized the effector 127 candidates by selecting the candidates that followed the highest parameters. We 128 identified a novel candidate effector family with a conserved motif -WAxR among 129 several effector candidate members in Puccinia strüformis and other Puccinia species. 130 We further characterized two effector candidates possessing WAxR motif from Puccinia 131 strïformis Yrg rust fungi using cell death suppression assay, localization, and site132 directed mutagenesis. The present study is the first report of identifying a novel rust133 specific effector family with conserved motif in several candidates and having a cell 134 death suppression role in rust fungi. 


\section{Materials and methods}

138 Fungal proteome sequences were downloaded from UniProt and Ensembl 139 database(https://fungi.ensembl.org/index.html). The $P$. strïformis and Puccinia 140 triticina proteome were used from the genomic resources generated by Kiran et 141 al.,(Kiran et al., 2017, 2016). The infection of $P$. striifromis was done using a susceptible

142 variety of wheat (Agra Local). The samples were harvested at different time periods 1, 3, $1435,7,9$, and $14 \mathrm{dpi}$ (day post inoculation), immediately frozen in liquid Nitrogen, and 144 further used for RNA extraction. Nicotiana benthamiana plants grown up to 3-4 weeks 145 were used for agroinfiltration at $22{ }^{\circ} \mathrm{C}$.

2.1 Secretome analysis and functional annotation of fungal secretomes

147 Secretome analysis was performed using the online secretool pipeline (Cortázar et al., 148 2014). The non-classically secreted proteins were identified using SecretomeP 2.0

149 software by using proteome that was not predicted to be classically secreted 150 (http://www.cbs.dtu.dk/services/SecretomeP/). The annotation of secretory proteins 151 was done using NCBI- CD search(Lu et al., 2020). The proteins with no hits were 152 considered as unannotated secretory proteins.

$153 \quad 2.2$ Identification of CWDEs, known effector proteins, and virulence factors 154 across fungal secretomes

155 Identification of CWDEs was done using the dbCAN database and NCBI CD search 156 (Marchler-Bauer and Bryant, 2004; Yin et al., 2012). The known fungal effector, 157 virulence factor possessing conserved domain was identified by NCBI-CD search. The 
PHI-base plant interaction database was used to identify pathogenicity genes and virulence factors (Winnenburg et al., 2006).

\subsection{Phylogenetic, sequence and structure prediction analysis}

Phylogenetic analysis of the CSEPs family members identified from $P$. strïformis was done using the maximum likelihood (ML) method. MEGA 7.0 software was used for analysis, models were generated and the best available model was used with 1000 bootstrap runs(Kumar et al., 2016). The sequence alignment was done using MAFFT (https://mafft.cbrc.jp/alignment/server/). Structure prediction analysis was done using PHYRE2 software (Yang et al., 2015)

\subsection{Orthologous gene identification and selection pressure analysis for common gene clusters}

The comparison of orthologous genes in pathogen secretome was done using Orthovenn software (Wang et al., 2015). The genes present in the central cluster were used for the selection pressure analysis. Only one gene was taken from each class as a representative member if there were multiple paralogous genes in one organism in the central cluster. The selection pressure was analyzed using DnaSP 5.0 software (Librado and Rozas, 2009)

\subsection{Prioritization of CSEPs by combining known benchmark features of effectors}

The unannotated secretome of fungal pathogens was screened for potential effector properties using the EffectorP 1.0 (Sperschneider et al., 2016). The secretome was further analyzed for small size (upto3oo amino acids) and cysteine content of $\geq 3 \%$ 
180

181

182

183

184

185

186

187

188

189

190

191

192

193

194

195

196

197

198

199

200

201

using CLC genomics. To find out nuclear localization signal (NLS), and repeat sequences, fungal secretomes were further analyzed by different softwares like Nucpred (Brameier et al., 2007) (NLs identification), localizer (Sperschneider et al., 2017) (localization), xtreme (Newman and Cooper, 2007) and T-rek (Jorda and Kajava, 2009) (repeat identification). To increase the confidence of $\mathrm{NL}$ and repeat prediction, common sequences predicted by all four softwares were selected for further analysis. The sequences which contained all the four parameters i.e. high effectorP, small size, NLS and repeat was prioritized $100 \%$, if three parameters followed then $75 \%$ and two paramteres then $50 \%$. The analyzed proteins were considered as effector, if followed at least any two parameters (50\%).

\subsection{Motif analysis, amino acid usage and expression analysis of CSEPs}

The motif analysis of fungal effector proteins was done by using the MEME suite (Multiple Em for Motif Elicitation)(Bailey et al., 2009). The maximum number of motif identification was restricted to 10 . The occurrence of the motif was set to any number of repetitions. The minimum motif width was set to 3 and a maximum of 50 . The motif that showed a similar motif pattern was analyzed separately to get a deeper insight into motif similarity. The amino acid usage of the effectors was analyzed by calculating the number of amino acids of the mature fungal effector proteins (without signal peptide). The expression of the prioritized fungal effector was analyzed by using expression data available publically in different studies and using a rust expression browser(Adams et al., 2021). 


\subsection{Identification of WAxR like motif-containing effector candidates in}

\section{other rusts and plant pathogen secretome}

The WAxR effector candidates identified in P. striiformis Yrg were used as a query for BLASTp against secretome and predicted proteome of various rust and other plant pathogens analyzed in the study. To further identify the WAxR like effectors in species not analyzed in this study, the BLASTp was also done using conserved region around WAxR motif (10-20 amino acids) as a query against NCBI nr database. The secretome of rust pathogens other than analyzed in the study was also identified as described in section 2.1. The unannotated secretory proteins from the various rust species were analyzed for the WAxR motif using the FIMO tool (https://memesuite.org/meme/tools/fimo).

\subsection{Cloning and expression of candidate effectors}

Three WAxR motif-containing candidate effectors Pstr_11677, Pstr_09735, and Pstr_o7126 were selected for cloning based on the prioritization list of the $P$. striiformis. The primers were designed for a full-length coding sequence of the candidate effectors (without signal peptide encoding region). The first-stand cDNA was synthesized using $1 \mu \mathrm{g}$ RNA isolated from $P$. striformis infection wheat samples from various time intervals $1,3,57,9$, and 14 dpi. The PCR of the candidate effectors using cDNA of various intervals was done. The candidate genes were cloned in pENTR/D/Topo vector, confirmed using PCR restriction digestion and sequencing studies. The confirmed pENTR plasmid clones were used for mobilizing the candidate gene CDS sequence in plant binary vector pGWB408 for overexpression studies and pGWB441 for localization studies using LR clonase II enzyme mix (vector provided by 
225 Dr. Tsuyoshi Nakagawa's lab). The confirmed plasmid clones for overexpression and 226 localization studies were transformed in agrobacterium strain GV3101 and further 227 confirmed by PCR before the agroinfiltration experiment.

2.9 Cell death suppression assay, subcellular localization site-directed mutation analysis

The confirmed agrobacterium clones containing overexpression construct were grown at $28{ }^{\circ} \mathrm{C}$. The final cultures were adjusted to an optical density (OD) of 0.4 using MES buffer containing $10 \mathrm{mM} 2 \square(\mathrm{N} \square$ morpholino) ethanesulfonic acid (MES), $10 \mathrm{mM}$ $\mathrm{MgCl} 2, \mathrm{pH} 5.6$, and $150 \mu \mathrm{M}$ acetosyringone. The experiment was performed in 2-3 leaves of one $N$. benthamiana plant. The BAX construct suspension was also adjusted to OD 0.4 and infiltrated $24 \mathrm{hrs}$ after candidate genes construct infiltration at the same spots. The pictures were taken after 5-7 days of infiltration. For subcellular localization studies, the agrobacterium culture was adjusted to 0.5 with a resuspension buffer. The

238 images were taken after $48 \mathrm{~h}$ at $516 \mathrm{~nm}$ using Carl Zeiss Confocal Microscope( 239 Germany). The point mutation in the WAxR motif was done using QuikChange II SiteDirected Mutagenesis Kit per manufacturers' instruction. The primers were designed using the Agilent mutation primer designing tool. The mutations of the WAxR motif were carried as follows: W (tryptophan) to alanine, A (alanine) to aspartic acid (D), and using sequencing and further mobilized into pGWB408 and pGWB441 for 


\section{Results}

\subsection{Secretome analysis and functional Annotation of fungal Secretomes}
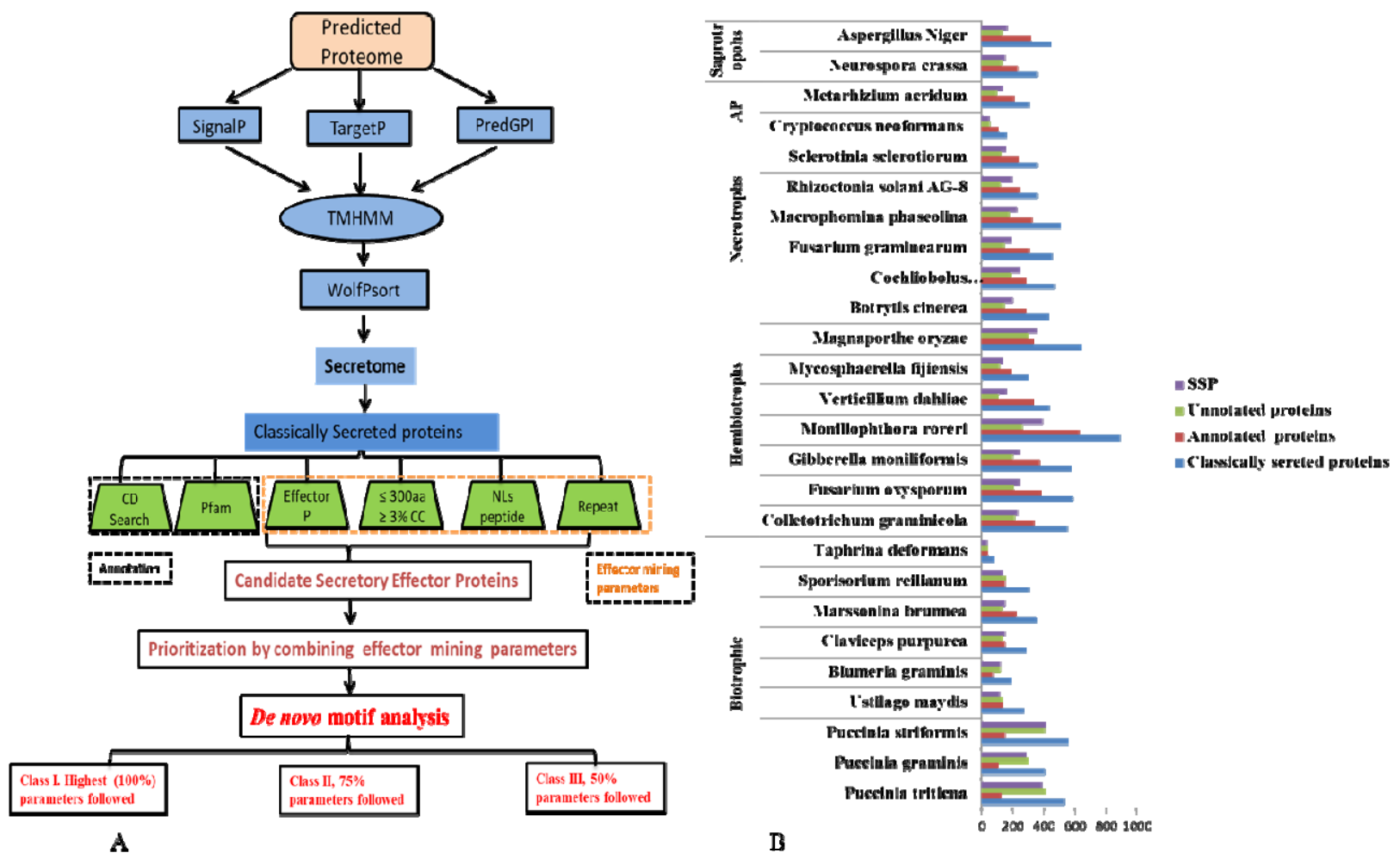
258

259

260

261

262

263

264

265

266

267

268

269

270

271

272

273

274

275

276

277

278

279

pathogens. (B) comparison of Classically secreted proteins, annotated unannotated proteins, and Small secretory proteins (SSPs) of various plant pathogens.

The annotation results of the predicted fungal secretome were consistent with the previous studies and showed that the secretome of obligate biotrophic pathogens contains the highest unannotated proteins. The rust fungi and powdery mildew pathogen were abundant in these proteins and there were $76 \%, 74 \%, 73 \%$, and $62 \%$ of unannotated proteins for $P$. triticina, $P$. graminis, $P$. strïformis, and B. graminis, respectively. No other pathogens had the secretome that was $>50 \%$ uncharacterized (Supplementary Table S1).

\subsection{Identification of CWDEs, known effector proteins, and virulence factors} across fungal secretomes

The identification of CWDEs and known effectors and further comparison was done to find out the differences across different classes of pathogens. The analysis showed the presence/absence of different classes of CWDEs. The lowest no. of CWDEs was found in all the three rust fungi, particularly in P. striformis secretome (Figure 2A). It was interesting to note that, even other biotrophic pathogens like B. graminis, C . purpurea, and U. maydis (UM) had higher CWDEs in comparison to the rust fungi (Figure 2A).

In the case of hemibiotrophs, the highest CWDEs were found specifically in Verticillium dahliae (VD) and Monilithphora rorei (MR) that contain $47.61 \%$ and 44.27\% of total secretome, respectively. Except for few pathogens in necrotrophs, saprotrophs, and animal pathogens, most of them follow a similar trend to each other in their respective class (Figure 2 A). Various known effectors and virulence factors, like 
Chorismate mutase (CM), CFEM, FKBP, LysM were also identified in all pathogens.
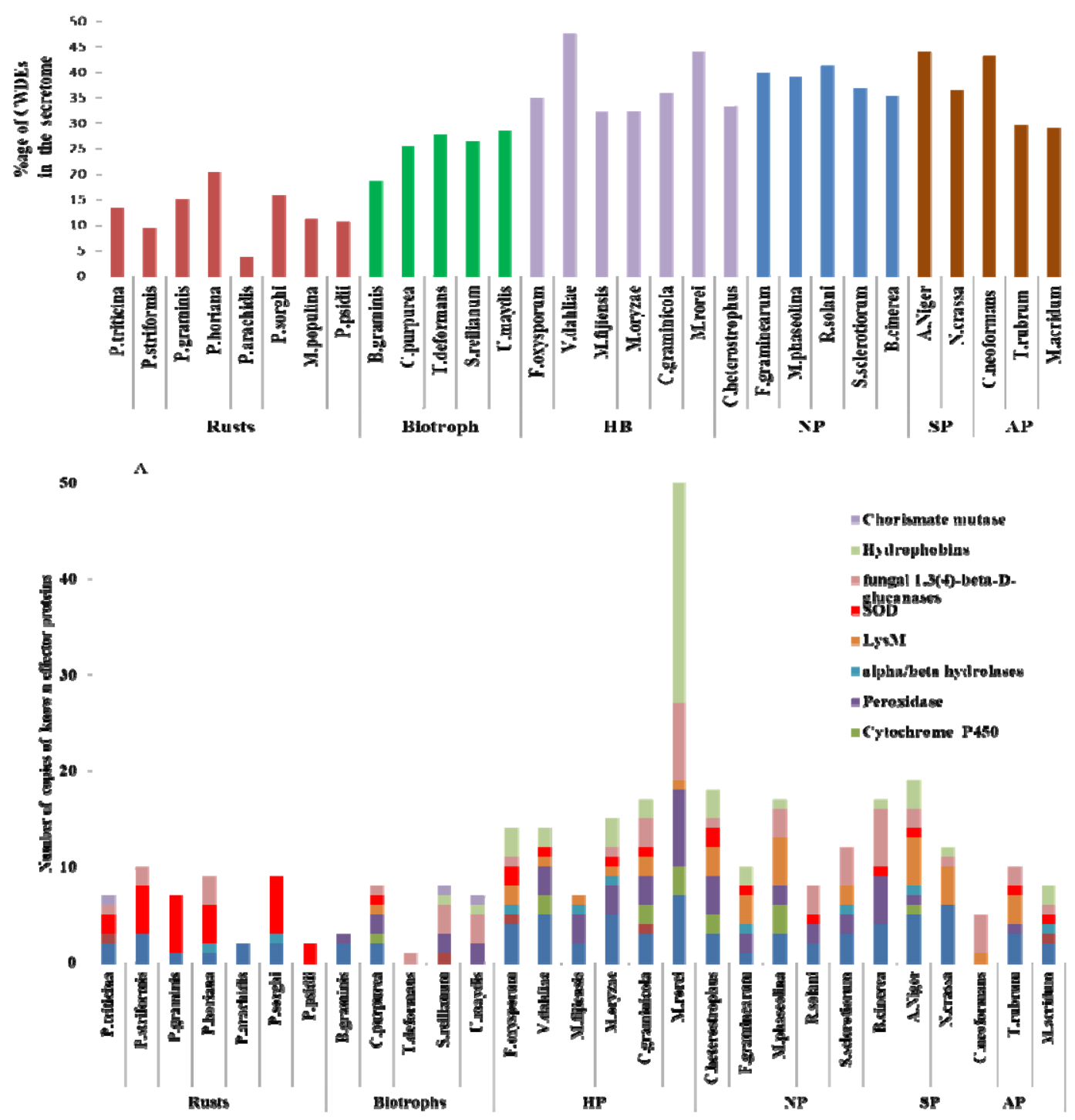
B

Fig. 2. Comparison of CWDEs and known effector and virulence factors in various 284 fungal species. (A). Number of CWDEs found in the secretome of various plant pathogens. Rust fungi encode the lowest CWDEs in the secretome. (B) The number of 286 known effector proteins present in the various plant pathogens. (HB/HP287 hemibiotrophs, NP- necrotrophs SP-saprotrophs, AP-animal pathogens). 
No LysM proteins were found in biotrophs while the highest number was found in Macrophomina phaseolina (MR) (5). When mining for SOD, the rust fungi contained the highest number across all pathogens studied. (Figure 2B). In addition to this, fungal hydrophobins were also studied and were present in the range of $0-3$ in most of the pathogens but, surprisingly, 24 hydrophobins proteins were present in MR Secretome (Figure 2 B).

\subsection{Prioritization of identified CSEPs}

295

296

297

298

299

300

301

302

303

304

305

306

307

308

309

The parameters mentioned in the materials and methods section (2.5) were combined to prioritize the effector proteins. The analysis identified several effectors in all three major classes of pathogens (Figure 3A). The highest CSEPs were found in P.strïformis (218, 43\%) followed by C. purpurea (109, 37\%) and P. triticina (161, 30\%) (Fig. 3A). Overall, the biotrophs had the highest number of CSEPs and most of them were unannotated. The CSEPs were then classified into three categories: following all the four parameters (100\% score), following any three parameters (75\% score), or 2 parameters ( 50\% score). The candidates with a 100 and 75\% score were selected for further analysis. The prioritization analysis results revealed there were 4 proteins in $P$. striformis, 2 proteins in $M$.fijensis, and one protein in P. triticina, C. graminicola, $M$. oryzae, and $B$. graminis in the $100 \%$ score category. There were $77 \%, 11.8 \%, 14.3 \%, 12.7 \%, 6.2 \%, 6.7 \%$ proteins in B. graminis, $P$. triticina, $V$. dahliae, $F$. oxysporum $C$. heterostrophus, $P$. striformis, and M.oryzae respectively that followed $75 \%$ score (minimum 3 parameters of CSEPs prioritization). The remaining predicted CSEPs were present in 50\% score (two parameters) that followed effectorP score and small size high cysteine content or NLS as a CSEP parameter (Figure 3B ). 
M. burnnea had a high number of CSEPs in the third category (97.1\%) followed by
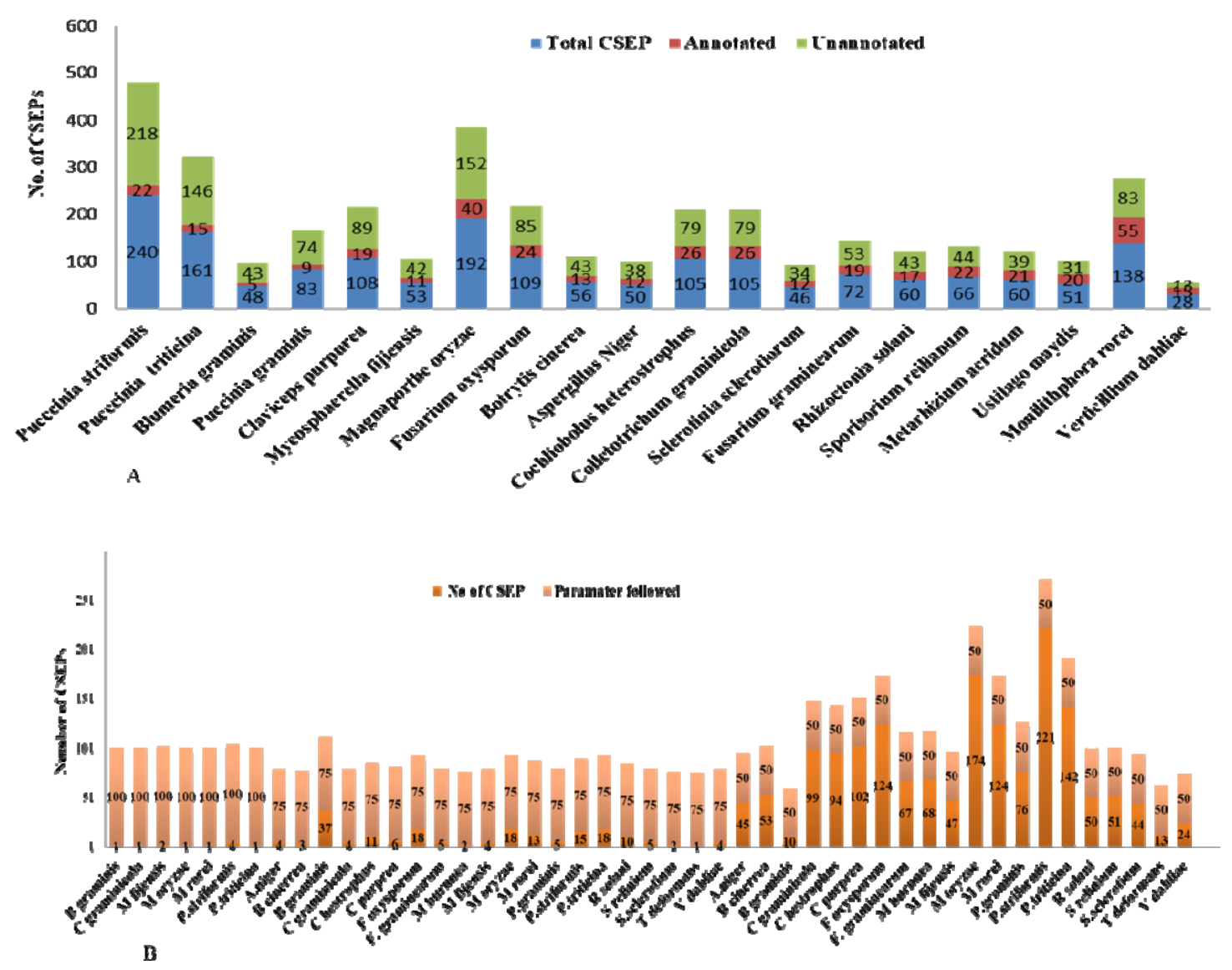
following 4 parameters. $75 \%$ score for following 3 parameters and $50 \%$ score for 319 following 2 parameters). 


\section{$321 \quad 3.4$ Expression analysis of candidate effectors}

322 The FPKM values (taken from publically available supplementary data from various

323 studies) plotted showed various CSEPs showed high expression suggesting the role of 324 these candidate effector genes in pathogenesis and disease progression. In the case of $P$.

325 striformis, out of the four genes that followed 100\% score, one CSEP (Pstr_o7126)

326 showed very high expression in germinating spores stage, and at 7, 9, and $11 \mathrm{dpi}$ (Fig.

$3274 \mathrm{~B})$. The other two genes present in the $75 \%$ score category showed high expression

328 Pstr11677 and Pstr_o9735 ( Figure 4 B). In the case of B. graminis, out of $77 \%$ CSEP 329 (37CSEP), 15 proteins showed high expression while 7 genes showed moderate 330 expression.at 6,12,24 and 48hpi (Fig. 4C). The expression analysis of CSEPs candidates

331 for $M$. oryzae, C. graminicola, F. graminearum, and B. cinerea also showed that 332 multiple CSEPs encoding genes were high in expression in the infection cycle ( 333 Supplementary Fig S1- S5). 


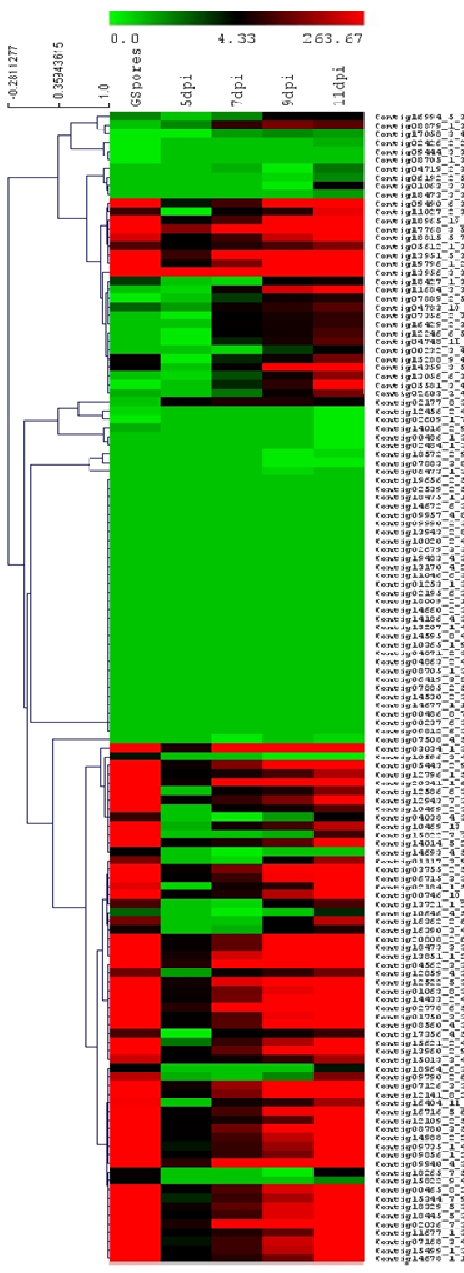

A
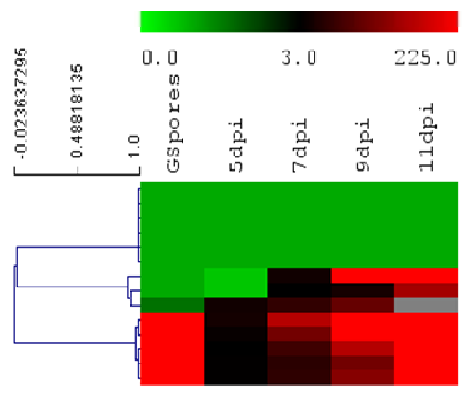

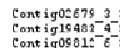

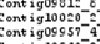

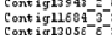

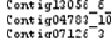

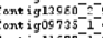

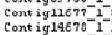
B
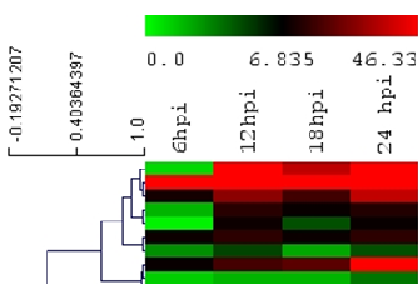

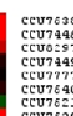

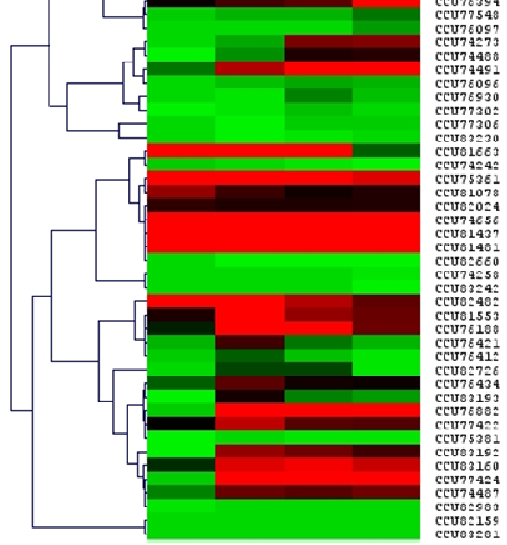

C

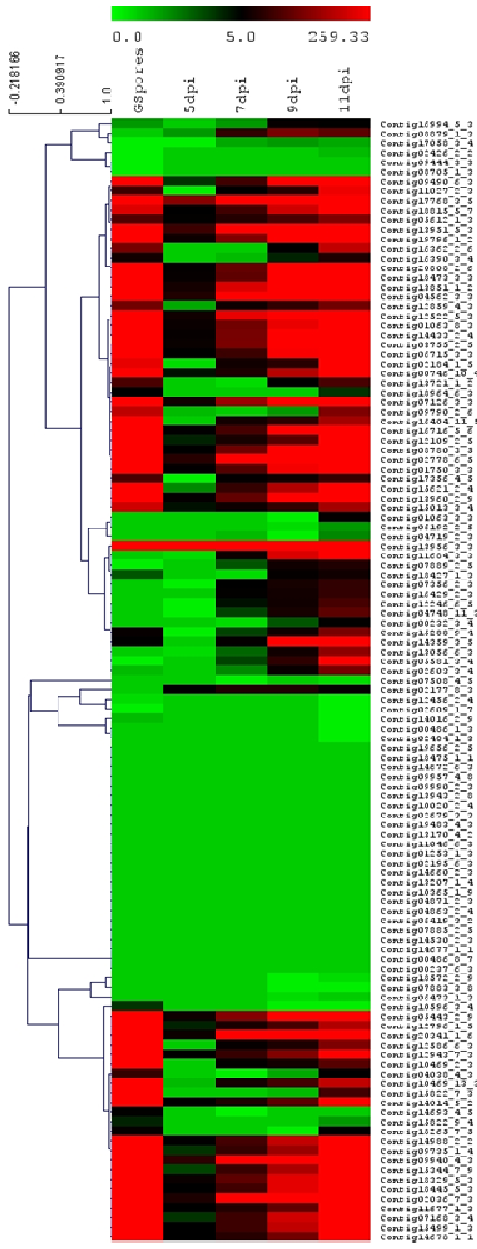

D

Fig. 4. Expression analysis of CSEPs of selected plants fungal pathogens. (A) Expression analysis of CSEPs identified from $P$. strïformis Yr9. (B) Heat map of expression values 


\subsection{Sequence and conserved motif repeat and amino acid usage analysis}

The conserved motifs were found both at the C-terminal and $\mathrm{N}$-terminal in the case of P. striiformis (Fig. 5A) and Claviceps purpurea, however, no specific conservation was identified in most of the CSEPs of other fungal pathogens. Among the analyzed CSEP in C. pupurea, 3 conserved motifs found in, motif 1 , motif 2 , and motif 3 were present in 23 proteins covering the full region of all these proteins. (Supplementary Fig. S6 and S7)
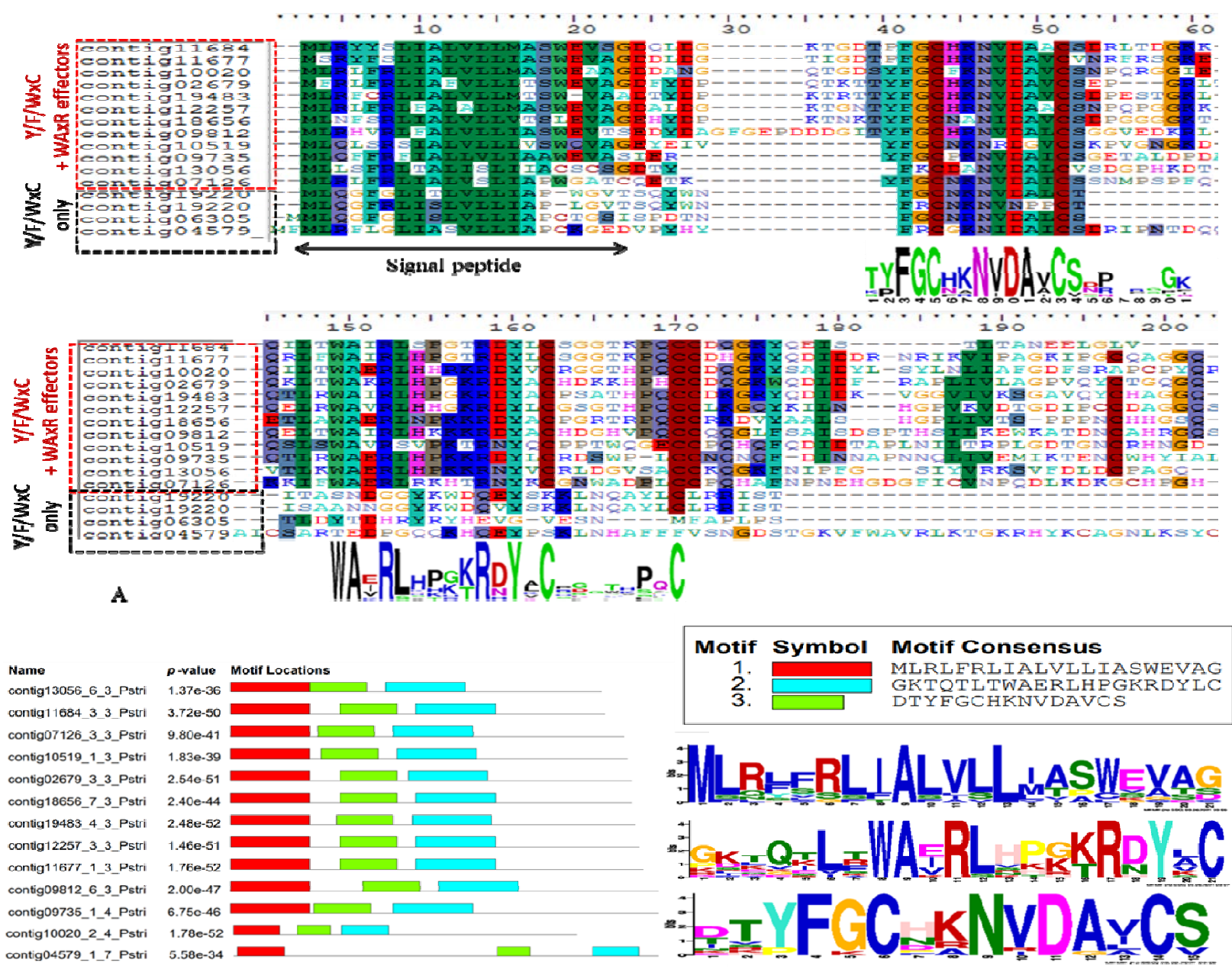

B

Fig. 5. Multiple sequence alignment and motif analysis of WAxR motif effectors from $P$. strïformis. (A) Multiple sequence alignment of effector proteins of P. strïformis Yrg. 
352

353

354

355

356

357

358

359

360

361

362

363

364

365

366

367

368

369

370

371

372

373

374

showing $\mathrm{Y} / \mathrm{F} / \mathrm{WxC}$ at $\mathrm{N}$ - terminal and WAxR motif at C-terminal. (B). De novo motif analysis identifying WAxR (Cyan) and FGC (green) motif in P. strïformis effectors, signal peptide (red).

The multiple sequence alignment of these proteins also shows significant conservation of amino acid residues specifically 6 cysteine conserved residues that were present in most of these proteins (Supplementary Fig. 6). The $P$. strïfromis CSEPs had the second-highest motifs of all the pathogens studied. Out of 218 CSEPs given as input, MEME returned 48 proteins with motif prediction. Motif 2 was present in 16 proteins at the N-terminal, after signal peptide. Motif 3 was present in $13 P$. striformis CSEPs. It was interesting to note that motif 3 was always found associated with motif 2 in 13 proteins. To further gain insight into these motifs, 13 proteins containing these motifs were further subjected to MEME suite and resulted in the identification of three major motifs (Figure 5B). The first motif (red) was the signal peptide region for these proteins. The second motif was the FGC motif, while the third motif was the WAxR motif in the 13 proteins (Figure ${ }^{\mathrm{B}}$ ). The multiple sequence alignment analysis also showed these 13 proteins to significantly conserved residues for the FGC region ( $\mathrm{Y} / \mathrm{F} / \mathrm{WXC})$ followed by the WAxR region (Figure 5A). Out of the four 100\% prioritize proteins for P. striiformis, Pstr_07126 was the only WAxR motif-containing protein while other WAxR effector proteins (Pstr_11677 and Pstr_09735) were from the 75\% score category.

The repeat analysis of CSEPs showed that the lowest repeats in CSEP (4.8\%$11.25 \%$ ) were present in rust pathogens and $F$. graminearum particularly in $P$. graminis while the highest was contributed by $V$. dahliae (75\%) followed by $S$. sclerotium (58.69\%) and $U$. maydis CSEP (55\%) (Supplementary Fig. S7). The amino acid usage 
375 analysis showed there is no such preference for amino acid usage between effector and

376 non-effector candidates except for cysteine (Supplementary Fig. 8).

$377 \quad 3.5$ Identification of $W A x R / W A x R$ like effector candidates in other rusts 378 and plant pathogen genome

379 The total 5000 BLAST (BLASTp) hits were analyzed against the WAxR motif for plant

380 fungal pathogens other than rust using the NCBI-nr database. Several proteins showed 381 the presence of the WAxR or WAxR like motifs however none of the proteins were 382 secretory nor effector in the analysis except rust fungi. The identification of WAxR like 383 effectors in rusts species apart from analyzed species showed the presence of a large 384 number of WAxR like effectors in their genome. The highest number of WAxR effectors 385 were found in P. strïformis $104 E$ (56 proteins) followed by 50 WAxR like candidates in 386 M. populina, (Fig. 6 A). 


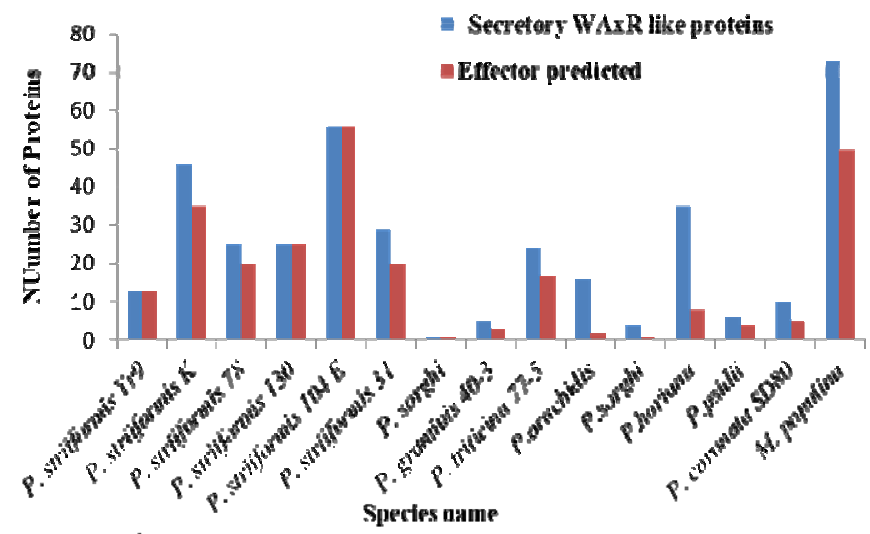

A

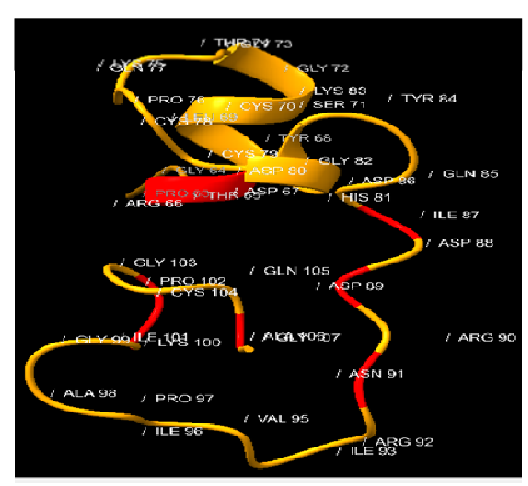

c

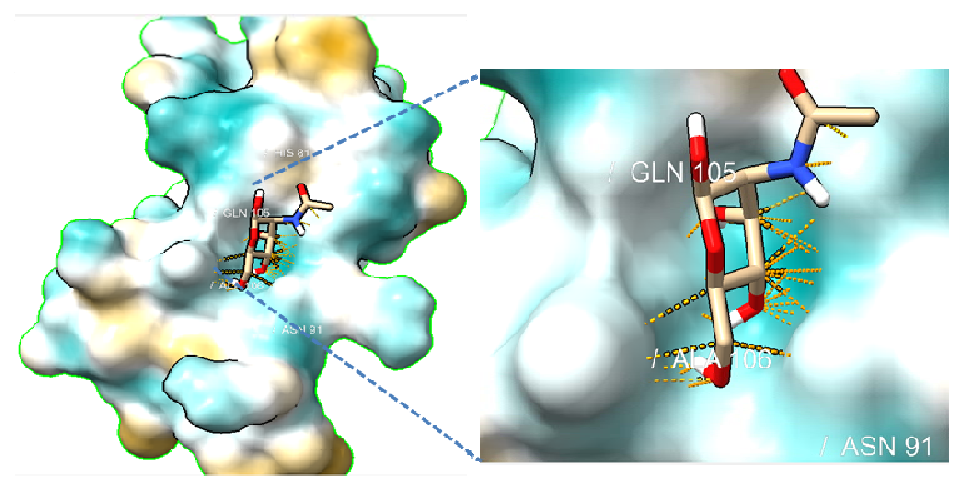

D

E

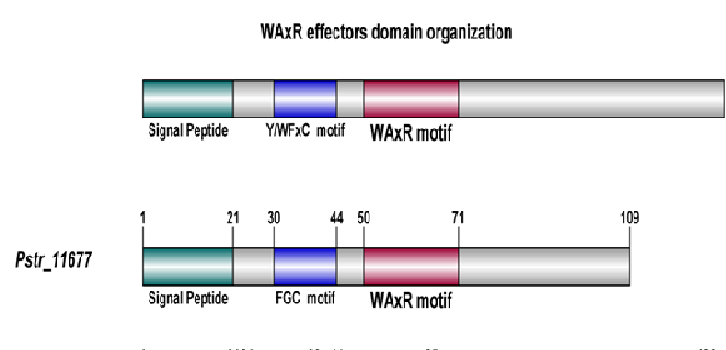

Pst__09735

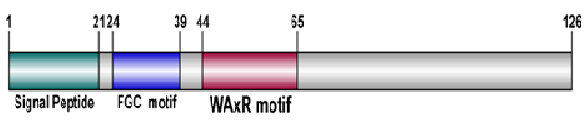

B

Fig.6. Identification WAxR like effector, domain organization analysis. (A) Identification and comparison of WAxR like effectors in various rust fungi. (B) General domain organization of WAXR effectors in rust fungi. (C) Structural modeling of Pstr_11677 showed similarity to chitin-binding protein. The modeled residues of Pstr_11677, red area show pocket of chitin-binding residues. (D) and (E) Molecular docking of Pstr_11677 showing binding of chitin (NAG).

Among all, the $P$. sorghi secretome showed the presence of only one WAxR like effector. Further, the domain organization analysis showed most of these proteins possess two major domains. First, the $\mathrm{Y} / \mathrm{F} / \mathrm{WxC}$ motif-containing region that was consistently present at the $\mathrm{N}$-terminal after the predicted signal peptide followed by the 
C-terminal WAxR motif region in the majority of rust WAxR effectors (Fig. 6B). The Cterminal region after the WAxR motif region was relatively less conserved in these

400 proteins.

401

The structural modeling of most of the rust WAxR effectors did not reflect any 402 similarity to known fold containing effectors or virulence proteins, however, in the case 403 of Pstr_11677, we found $26 \%$ sequence similarity to the chitin-binding protein of 404 Enterococcus faecalis with modeling confidence of $31.8 \%$ (Fig. 6C). The PDB sum 405 analysis also showed similarity to hydrolases with ligand-binding pocket for N406 acetylglucosamine (NAG) Further, the molecular docking of Pstr_11677 with chitin and

407 NAG showed significant binding energy $-4.8 \mathrm{kcal} / \mathrm{mol}$ predicting the putative function 408 of Pstr_11677 (Fig.6 D and E).

\subsection{Phylogenetic analysis}

412 (Figure $7 \mathrm{~A}$ ). To further analyze the group of WAxR proteins in other Indian $P$. 413 striiformis such as Race K, the phylogenetic analysis of WAxR candidates showed 414 clustering in phylogenetic analysis (Figure $7 \mathrm{~B}$ ). The phylogenetic analysis of WAxR and 415 WAxR like effectors identified from various rust fungi classified these into eight groups 416 (Fig. 8). 

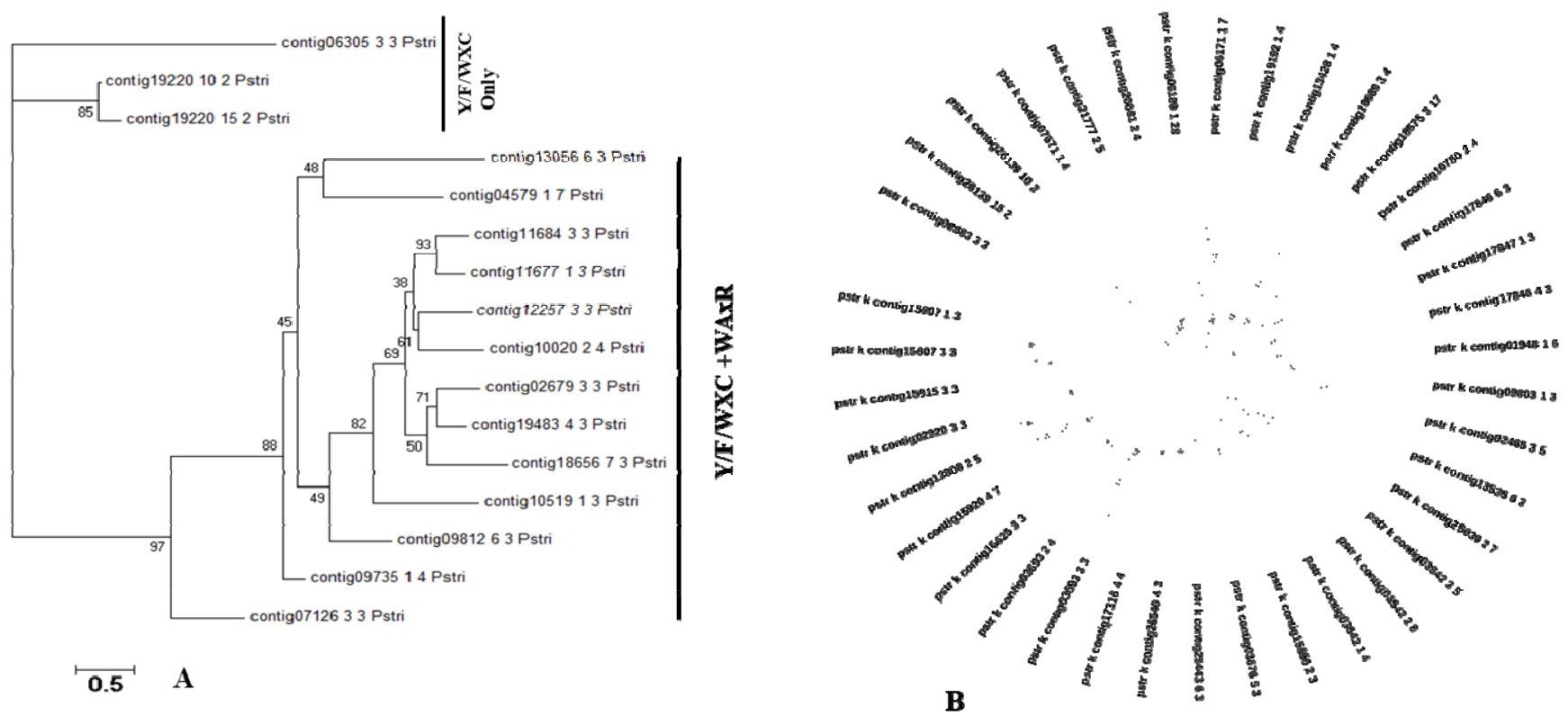

Fig.7. Phylogenetic analysis of candidate effectors of rust fungi. (A) Phylogenetic 419 analysis of WAxR motif-containing effector proteins present in P. striiformis Yrg. The WAxR and $\mathrm{Y} / \mathrm{F} / \mathrm{WxC}$ motif clustered separately from the effectors containing $\mathrm{Y} / \mathrm{F} / \mathrm{WxC}$ 421 motif alone (B) Phylogenetic tree of WAxR effector candidates identified from $P$. 422 strïformis Race K.

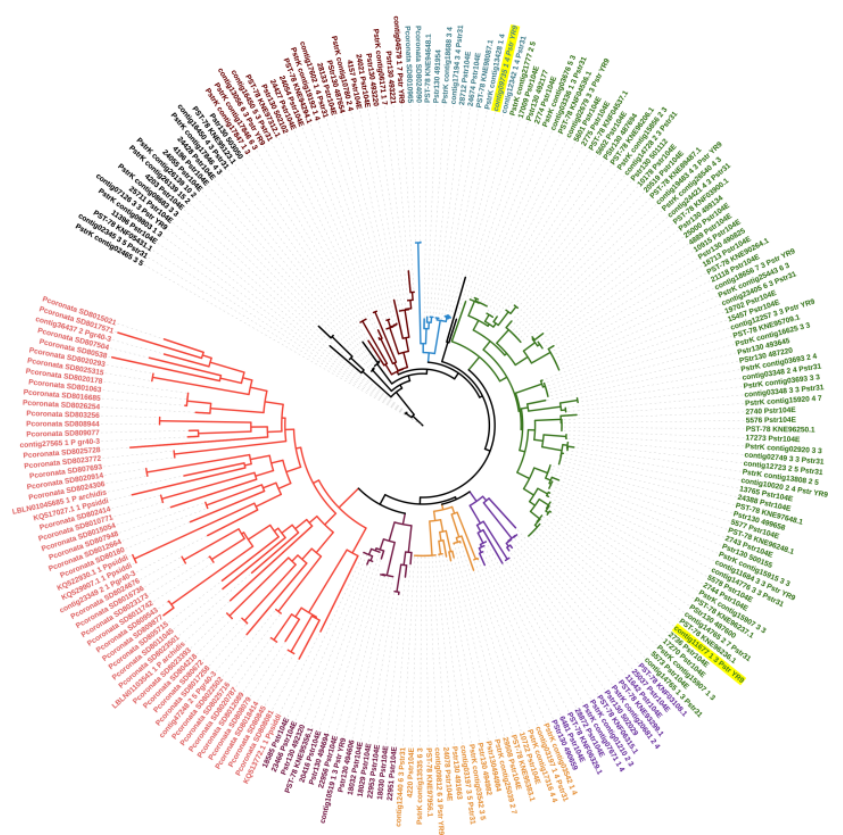


424 Fig. 8. Phylogenetic analysis of candidate effectors of rust fungi. The phylogenetic

425 analysis of all WAxR and WAxR like effectors of rust fungi using the maximum

426 likelihood method (ML) divided these proteins into eight groups (denoted by the

427 different colors). The yellow highlight proteins are the candidates characterized in the 428 present study.

\subsection{Orthology and selection pressure analysis}

430 The secretome of all fungal pathogens analyzed using orthovenn software revealed most

431 of the genes to be unique, present in singleton for each species. However, few genes

432 were common and present in the central cluster. Three major classes' necrotrophs,

433 biotrophs, and hemibiotrophs revealed 15, 3, and 13 common genes respectively.

434 Further, the selection pressure analysis of these genes identified 4,1 and 7 genes in

435 necrotrophs, biotrophs, and hemibiotrophs that were on positive selection pressure

436 respectively. The genes that were on selection pressure were mostly glycosyl hydrolase

$437(\mathrm{GH})$ belonging to class 1, 12, 18, and 61 alpha/beta hydrolases. (Table 1).

Table 1 Common proteins found in orthology analysis with positive selection pressure

\begin{tabular}{lcc}
\hline Class & Gene Family & $\mathrm{Ka} / \mathrm{Ks}$ \\
\hline Hemibiotrophs & Tyrosinases & 1.14 \\
& Glycosyl Hydrolase 61 & 1.28 \\
& Glycoside Hydrolase 18 & 1.15 \\
Alpha/beta hydrolases & 1.60 \\
& Glycosyl hydrolase 3 C-terminal domain & 1.32 \\
Necrotrophs & Glycosyl hydrolase family 12 & 1.44 \\
& Glycosyl hydrolase family 1 & 1.72 \\
& Pectinesterase and Fungal-type cellulose-binding domain & 1.20 \\
& Glycosyl hydrolase family 12 & 1.63 \\
Biotrophs & Fatty acyltransferase-like subfamily & 1.21 \\
& Alpha/beta hydrolases & 1.13 \\
& Peptidases S53 (sedolisin) family & 1.22 \\
& Hypothetical protein ( GO:0005576) & 1.17 \\
\hline
\end{tabular}


$440 \quad 3.7$ Cloning, cell death suppression assay, localization, and mutation of

\section{WAxR residues}

442 Out of three genes (Pstr_1726, Pstr_11677 and Pstr_o9735) two candidates, Pstr_11677

443 and Pstr_o9735 were successfully cloned. The transient overexpression studies of

444 Pstr_11677 and Pstr_o9735 studies showed no cell death-inducing phenotype, however,

445 both of these were able to suppress BAX-induced cell death in N. benthamiana(Fig. 9A

446 and B). The subcellular localization studies showed Pstr_11677 and Pstr_o9735 both

447 localized to the plant nucleus as well as the cytoplasm(Fig. 9C). Further, the mutation of

$448 \mathrm{~W}, \mathrm{~A}, \mathrm{R}$ residues from the WAxR motif did not affect the cell death suppressing capacity

449 nor the subcellular location of these effectors (Fig. 10). 


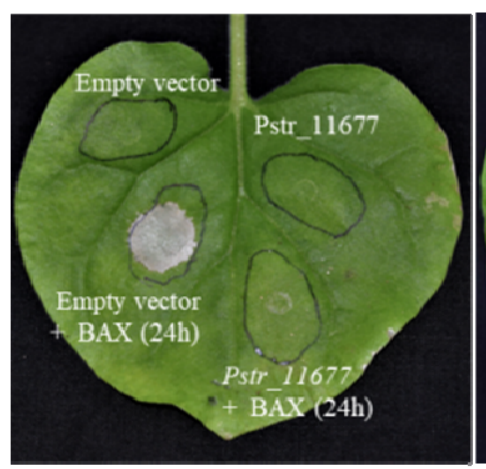

A

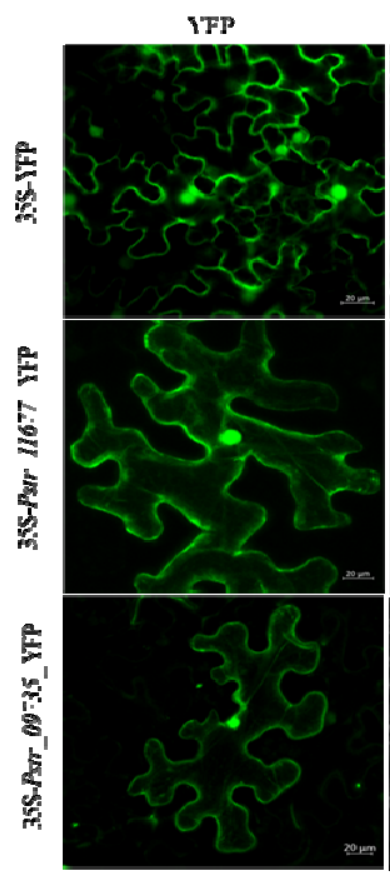

C.

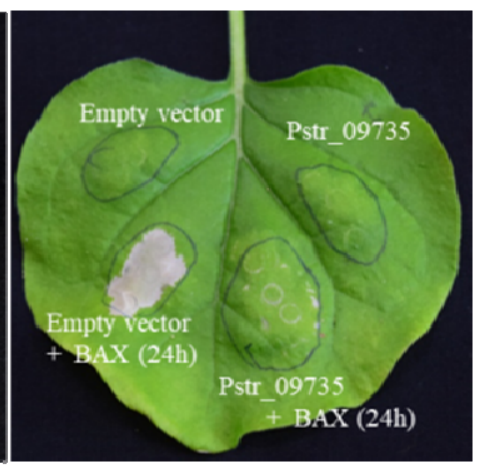

B

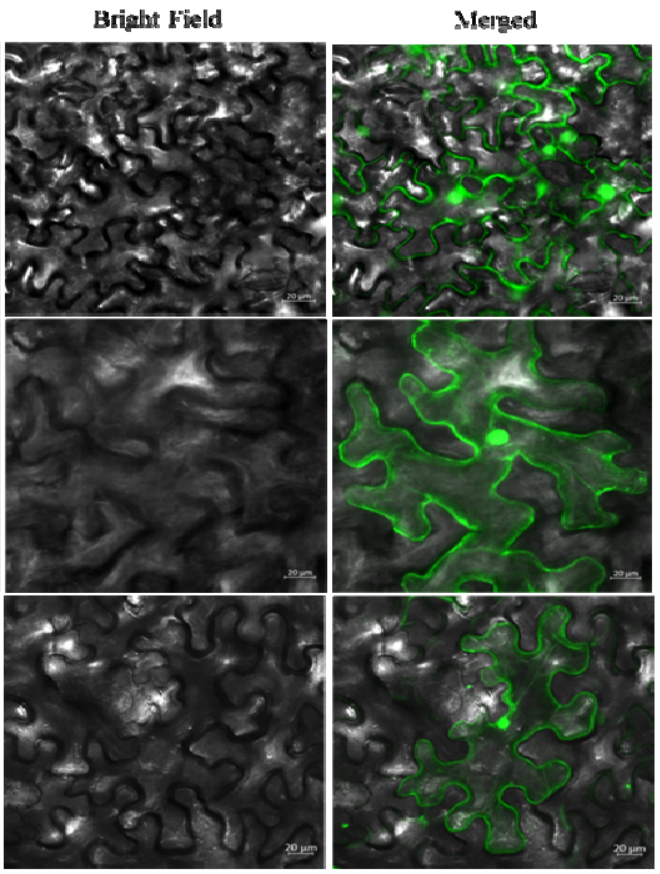

450

451 Fig. 9. Cell death suppression assay and subcellular localization of WAxR effector. (A)

452 and (B) BAX induced cell death suppression assay using transient agroinfiltration

453 transformation for Pstr_11677 and Pstr_o9735 WAxR effector from P. strïformis Yr9

454 race. (C) subcellular localization of Pstr_11677 and Pstr_o9735 showed these proteins 
Pstr_11677

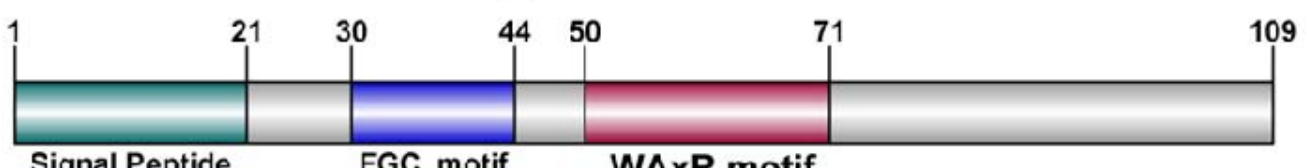

Signal Peptide $\quad$ FGC motif WAxR motif

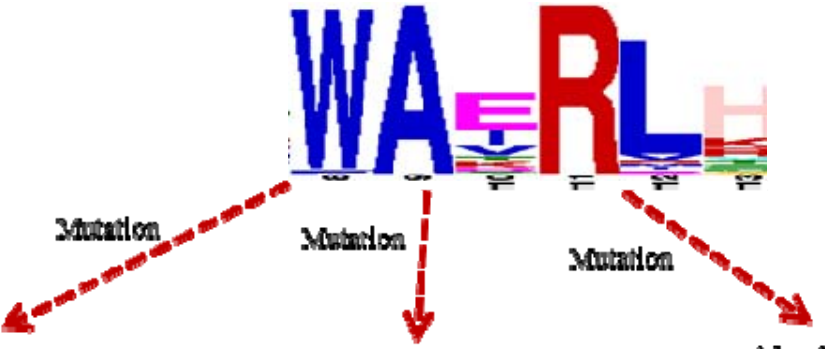

Alanthe (A)

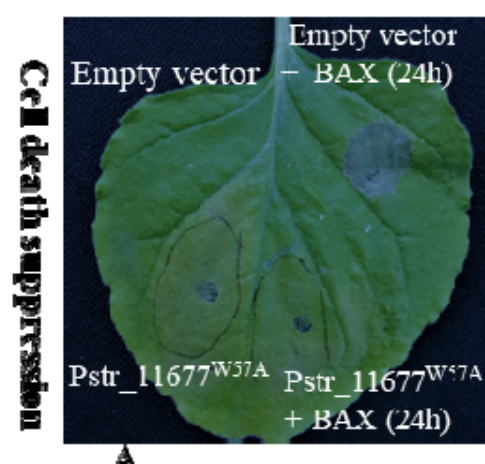

A

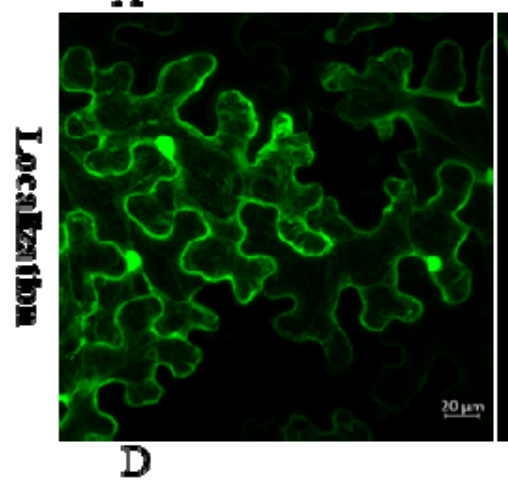

Aspartic acid (D)

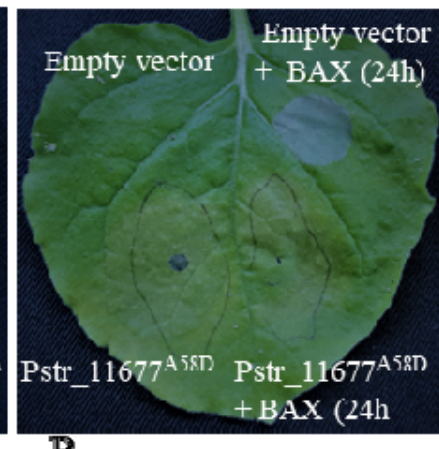

B

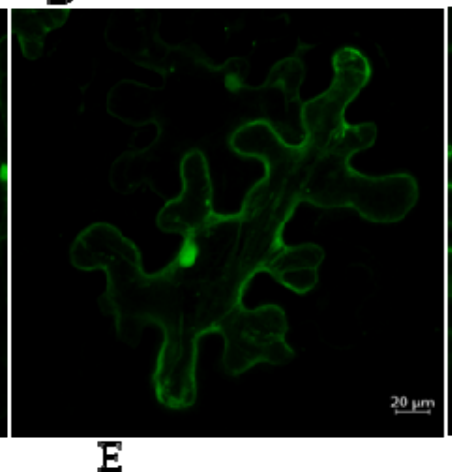

Alanine (A)
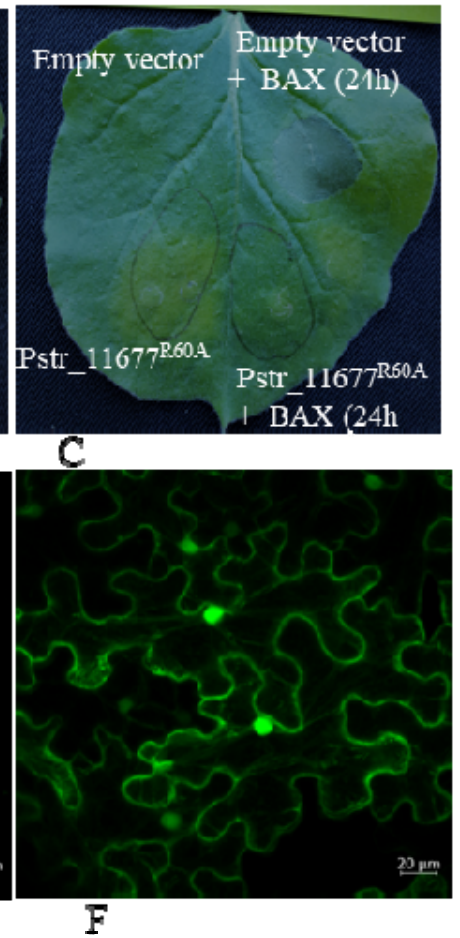

457 Fig. 10. Cell death suppression assay and subcellular localization of WAxR effector after

458 mutations of $\mathrm{W}, \mathrm{A}, \mathrm{R}$ residues. (A) and (D) Cell death suppression and localization of

459 Pstr_1167 ${ }^{\mathrm{W}_{57} \mathrm{~A}}$ mutation. (B) and (E) Cell death suppression and localization of

460 Pstr_1167 ${ }^{\text {A58D }}$ mutation. (C) and (F) Cell death suppression and localization of

461 Pstr_1167 ${ }^{\text {R60A }}$ mutation. 


\section{Discussion}

463

464

465

466

467

468

469

470

471

472

473

474

475

476

477

478

479

480

481

482

483

484

Secretion of proteins and transferring them to the host cell is one of the primary mechanisms of fungal pathogens to disarm the host. The host as well as pathogens both have a plethora of mechanisms to defeat each other in the war of survival. However, the pathogens have some advantages because of their small life cycle, large spore number, and ability to mutate easily. In addition to this, pathogen develops different mechanism in a unique and faster way to avoid host detection mechanisms than the host that are mostly unknown till now. Moreover, every plant fungal pathogen designs a consortium of secreted proteins that suits its nutritional needs and helps in conquering the host defense. High diversity and specific nutritional choices cause pathogens to have varied secretomes making it difficult to study.

In this study, we have identified, analyzed, and prioritize the CSEPs of various pathogens of different lifestyles. The identified secretome of pathogens describes various features like evolution, infection strategies, mode of nutrition, etc. The secretome analysis showed general trends that pathogens having dual lifestyles have a higher percentage of the secretome in comparison to others pathogens. The top three pathogens M.oryzae, M.rorei, C.graminicola three had the highest secretome of all and belonged to hemibiotrophic (HM) category (Fig.1 B). These results were also consistent with previous analysis (Lowe and Howlett, 2012) (Kim et al., 2016) and further confirmed that high proteome size did not correlate directly to high secretome size. In $U$. maydis only 6522 genes were present, but these genes accounted for $4.18 \%$ of secretome, surprisingly in one of the biotrophic rust fungi $P$. triticina (Kiran et al., 2016) had 32000 genes, however, its secretome accounted for $1.36 \%$ of the whole 
485

486

487

488

489

490

491

492

493

494

495

496

497

498

499

500

501

502

503

504

505

506

507

508

proteome(Fig 1B), but on the other hand, its non-classically secreted proteins was highest of all the pathogens (11480) (Data not shown). Overall, secretory proteins were highest in hemibiotrophs while animal pathogens have the lowest proportion of secretome. The higher secretome in hemibiotrophic pathogens can be supported by the fact that pathogens follow a dual lifecycle where the biotrophic phase requires multiple small secretory proteins that are mostly unknown for restricting the action of the host without causing significant damage and later on require toxins and hydrolases for the killing of the host (Fig.1B and Supplementary Table S1). The biotrophic pathogens especially rust fungal pathogens mostly have high SSPs and unannotated proteins was also reflected in our studies as $P$. graminis and $P$. strifromis has highest SSP followed after M.oryzae (Fig. 1B). The CWDEs has also an indispensable role in fungal pathogenesis. Previous studies on CWDEs analysis by showed that necrotrophs and hemibiotrophs have high CWDEs than biotrophs. Similar results were also found in our results, with some exceptions like animal pathogens and saprotroph. C. neoformans and A. niger had CWDEs almost equal to necrotrophs and hemibiotrophs (Fig. 2A) .Although, all the biotrophic organisms contain lower CAZymes when compared with other pathogens, the obligate biotrophs; rust fungal pathogens and powdery mildew showed, even more, less number of CAZymes and high SSP than other biotrophs(Fig. 2A). The results also implied that obligate biotrophic pathogens use less vigorous mechanisms to invade the host and use much more specific ways than other biotrophic pathogens like $U$. maydis and $C$. pupurea. In addition to CWDEs, multiple virulence factors also help in the shaping of the secretome of pathogens. We found a varied number of CFEM effector proteins in all pathogens implying the importance of this effector in pathogenicity (Fig. 2B). Though the function of CFEM effector has not been 
509

510

511

512

513

514

515

516

517

518

519

520

521

522

523

524

525

526

527

528

529 530

entirely known till now, it has been known to play functions like signaling, host surface adhesion, and role in infection structure development in multiple pathogens(Liu et al., 2019; Zhao et al., 2020; Zhu et al., 2017). Recently BcCFEM1, a Botrytis cinerea CFEM containing proteins is reported to perform multiple functions like stress tolerance, conidia formation, and virulence (Zhu et al., 2017). A recent genome-wide identification has also highlighted a total of 24 CFEM domain-containing proteins however this number containing proteins with the transmembrane region(GONG et al., 2020). Additionally, our analysis showed that CFEM family members are not only restricted to pathogenic fungi but are also present in non-pathogenic fungi like N.crassa and even in high copy numbers supporting the role of the protein in the diverse processes (Fig. 2B).

The LysM fungal effectors are, present in multiple plants and animal pathogens and bind with chitin to surpass detection by the host defense system (Dubey et al., 2020; Kombrink and Thomma, 2013; Levin et al., 2017). Surprisingly our analysis revealed that this effector was absent in the secretome of biotrophic plant pathogens except for C.pupurea(Zhao et al., 2020) (Fig. 2B). The absence of this effector in these pathogens could be expected with the fact that in Uromyces viciae-fabae rust fungi, convert the chitin into chitosan using the chitin deacetylase gene when the mycelium of pathogens penetrates the host stomata (Deising and Siegrist, 1995). The change of chitin into chitosan leads to less affinity of host chitin-binding proteins causing a less vigorous immune response by the host (Deising and Siegrist, 1995). The other explanation could be given that; rust fungal pathogens may bypass this chitin-based detection using some other unknown mechanism. 
Among the various defense mechanisms used by the host, the generation of the oxidative burst has proven to be effective as it restricts the growth of pathogens in many ways. The different Reactive Oxygen species (ROS) produced by the host not only kill

534 the pathogen by damaging proteins lipids, cell components but also activates 535 hypersensitive response and play role in signaling pathways leading to activation of a network of defense response (Tenhaken et al., 1995; Torres et al., 2006). In our study, the rust fungal pathogens showed the highest number of SODs than all other pathogens (Fig. 2B). The presence of high SOD proteins in rust pathogens is evident by the fact that damage caused by ROS production causes resistance to host cells against biotrophs in combination with various metabolites, restricting the movement of pathogens to other cells by necrotizing that area. On the other hand, necrotroph pathogens survive these

542 conditions easily by secreting various enzymes and compounds like oxalic acid, catalase, peroxidase, etc. Moreover, necrotroph pathogens flourish easily in areas necrotized by the hypersensitive response, as they take nutrition from the dead cells only. (Able, 2003; Mayer et al., 2001; Rajarammohan, 2021). In addition to this, recently Liu et., 2016 have shown that $\mathrm{Zn}-\mathrm{SOD}$ of $P$. striformis is secretory and provides increased resistance against oxidative stress induced by the host to P.striformis (Liu et al., 2016).

548 Interestingly other biotrophs had no or very less SOD which indicates that rust fungal pathogens use these proteins as a crucial mechanism to tackle the host oxidative defense 550 than other biotrophs. Moreover, we also looked into the status of genes like 551 hydrophobins in the secretome of all pathogens that have reported a wide role in 552 virulence in other pathogens. The hydrophobin proteins have been described to play 553 multiple roles in filamentous pathogens. In A. fumigatus these proteins aid in fungal 554 spores to remain undetected from immune response and removal of these proteins by 
555

556

557

558

559

560

561

562

563

564

565

566

567

568

569

570

571

572

573

574

575

576

577

different methods causes spores detection leading to immune system activation (Paris et al., 2003). Metarhizium brunneum, also contains multiple hydrophobins genes, differentially express them and play a diverse role in pigment production, conidia production, hydrophobicity, and imparting virulence (Sevim et al., 2012). A hydrophobin gene of $M$. grisea is vital for its development, virulence, and colonization inside the plant (Kim et al., 2005). In our analysis, we found one to three copies of hydrophobin genes in most of the pathogens except $M$. rorei having 24 copies, highest of all studied pathogens (Fig. 2B). The extremely high number of hydrophobins in $M$. rorei showed that hydrophobins could be very important for pathogenesis, so eventually gone substantial expansion in course of evolution.

To look for genes that were common in pathogens and under evolutionary selection pressure, the orthologous genes were analyzed for selection pressure among different pathogens classes. Biotrophic pathogens had a single gene on positive selection pressure annotated as peptidases S53 (sedolisin) a serine peptidase (SP) (Table 1). The SP may be one of the important candidates to target by the host as these have been known to cause direct interaction with the host by degrading the cell wall and pathogenesis-related proteins of multiple hosts and helps in the colonization of pathogens (Orts and Ten Have, 2018; Reichard et al., 2006).

As hemibiotrophic and necrotrophic pathogens are more vigorous in action against the host, the prime barrier that prevents entry of these pathogens inside the plant host is the cell wall. The removal of this barrier requires the expression of various cell wall degrading enzymes like Glycosyl hydrolases (GH) for both classes of pathogens enabling direct contact of these GH with the host (Gruber and Seidl-Seiboth, 2012; 
578 Kubicek et al., 2014; Palomares-Rius et al., 2014). Proving this fact, the hemibiotrophic

579 pathogens had seven genes on positive selection while necrotrophs had three, mostly belonging to the GH category (Table 1). The presence of two common genes GH12 and alpha/beta hydrolases in necrotrophs and hemibiotrophs showed these genes may be associated with necrotrophic mode of nutrition for these pathogens. The GH12 of hemibiotrophic oomycete pathogen Phytophthora sojae acts as virulence factors having xyloglucanase and $\beta$-glucanases activity (Ma et al., 2015). In addition to this, GH12 also triggers pathogen-associated molecular patterns (PAMPs) immunity and causes cell death, when expressed in soybean, Nicotiana benthamiana, and other members of the solanaceae family (Ma et al., 2015). In another hemibiotroph fungus $V$. dahliae, two virulence factor, activating PAMP immunity (PTI) in the host and causes cell death (Gui et al., 2017). Another gene on selection pressure was GH61, now called copperdependent Auxiliary Activity family 9 (AA9) is a weak cellulose-degrading enzyme that 592 enhances the hydrolysis of lignocellulose when used along with the other 593 lignocellulolytic enzymes (Karnaouri et al., 2014).

The sequence-based periodization process returned various CSEP candidates in the analyzed secretome from the different classes of pathogens (Fig. 3B). Every CSEP 596 candidate followed multiple parameters, so the chances of being an effector also get 597 increased up to some extent. The MEME analysis of CSEPs revealed conserved motifs in 598 some of the biotrophic pathogens like C. pupurea and P. strïformis (FGC WAxR, 599 P.striiformis) and CTPG, C. purpurea) (Fig5 A and S6). Moreover, the phylogenetic 600 analysis of all the 230 WAXR/ WAxR like proteins proved that these effectors are most 
601 probably associated with some common families in these pathogens as these clustered 602 in eight groups. Similar to the RxLR effector the WAxR effector could be involved in the 603 diverse defense manipulation process as these proteins show high sequence diversity 604 except at the WAxR motif region.

In biotrophs, very few conserved motifs have been found such as $\mathrm{Y} / \mathrm{F} / \mathrm{WxC}$ and 606 RxLR like motifs in P.strifromis, P.graminis genes eg. PS87 till now (Godfrey et al., 2010; Gu et al., 2011; Saunders et al., 2012). No other conserved motifs have been reported in rust CSEPs. The presence of WAxR motif-containing effectors in all major 609 stripe rust races presents worldwide implies these effectors are core candidates for these pathogens. The recently sequenced $P$. strïformis $104 \mathrm{E}$ race encoded 56 WAxR motifcontaining CSEPs suggesting the expansion of these effectors in $P$. strïformis or specifically in this race. In Indian P.striformis race $K$, Yr9, and 31 we found 35, 13, 20 WAxR effectors respectively suggesting these effectors are significantly present in their secretome. The race 104E has been sequenced with long-read sequencing technologies while other previously sequenced stripe rust genomes including race $\mathrm{K}$, race 78 race 130 616 are the result of short-read based assemblies, therefore, the WAxR effector members in 617 these races could be higher than current predictions. (Fig. 6A) Apart from P. strïformis, 618 the WAxR like effectors were also present in other rusts however comparatively less 619 number except for poplar rust $M$. populina that possesses more than 50 proteins. 620 However, it is worthy to note that these proteins were variants of WAxR effectors. 621 Further functional validation is required whether these suppress cell death similar to 622 WAxR effectors, Pstr_11677 and Pstr_o9735 identified from P. strïformis Yr9 or not. 623 The cell death suppression activity of WAxR effectors suggests that they play a crucial 
624 role in host defense manipulation as these effectors were able to suppress BAX-induced 625 cell death (Fig. 7A) To determine, whether the WAxR motif is specifically playing a role 626 in the effector function, the mutation of the individual residues $\mathrm{W}, \mathrm{A}, \mathrm{R}$ for both 627 Pstr_11677 and Pstr_o9735 was done however the individual mutations of these 628 residues did not alter its role in cell death suppression or localization. It could be 629 speculated that the complete WAxR motif region might have been involved in the cell 630 death suppression activity as three other residues arginine, tyrosine and cysteines were 631 present downstream of the WAxR motif (Fig. 5) form of FGC further suggested the function of these proteins in host manipulation. The $\mathrm{Y} / \mathrm{F} / \mathrm{WxC}$ have been previously known to be associate with haustoria forming pathogens specifically rust and powdery mildew (Godfrey et al., 2010; Ozketen et al., 2020; Xu et al., 2020). The transcriptomics of haustoria tissues in different studies has shown the association of $\mathrm{Y} / \mathrm{F} / \mathrm{WxC}$ with candidate effectors exclusively present in haustorial 638 tissue(Ozketen et al., 2020; $\mathrm{Xu}$ et al., 2020). Apart from the association with 639 haustorially expressed effector proteins the function of the $\mathrm{Y} / \mathrm{F} / \mathrm{WxC}$ motif remains 640 elusive. Moreover, very few WAxR candidates were devoid of the FGC motif in the study 641 suggesting the crucial function of both the motifs in respect to effector functions and 642 further stating that WAxR effectors could be expressed in haustoria. The expression 643 analysis also showed that one of the functionally validated WAxR effectors Pstr_11677 644 showed upregulated expression in haustoria compared to germinated spores. The 645 structural modeling of the Pstr_11677 showed similarity to the chitin-binding domain 646 further suggesting the effector function of the WAxR members. Moreover, several 
647 studies have reported that most of the N-terminal motifs are involved in the

648 translocation of the effectors similar to the RxLR dEER motif, and C- terminal domain

649 or motif are involved in cell death suppression or induction function (Petre and

650 Kamoun, 2014; Rastogi et al., 2019). Therefore it could be speculated that the FGC motif

651 is involved in the translocation of these effectors from haustoria to plant and the WAxR

652 region could be involved in the effector function (Godfrey et al., 2010). However, the

653 deletion analysis of these two motifs may highlight their specific functions. Overall the

654 identification of the FGC motif-containing WAxR effector family in rust pathogens may

655 provide a baseline and new opportunity to explore the specific function of these effectors

656 in host defense manipulation and utilization of these effectors in durable resistant

657 varieties development.

\section{Conclusions}

659 The secretomics of plant-pathogen has unraveled the complex infection strategies 660 through the understanding of effector proteins. However, these studies have been 661 largely hampered by the presence of novel effectors in secretome that often lacks 662 conserved features especially in the case of rust fungi. In the present study, using 663 comparative secretomics, we enlighten the effector proteins of plant-pathogen including 664 rusts. We concluded that rust fungi use minimum CWDEs, high SODs, and a novel C665 terminal WAxR motif associated with the $\mathrm{N}$-terminal $\mathrm{Y} / \mathrm{G} / \mathrm{WxC}$ motif in several 666 candidate effectors of $P$. striiformis and other rust fungi. The WAxR motif could be a 667 major component of the effector consortium of rust as it was present in several 668 candidate effector proteins having a possible haustorial association due to the presence 669 of the FGC motif. The WAxR effectors also suppress the cell death and localize to the 
670 nucleus and cytoplasm proving a crucial component of the defense manipulation system

671 of the host. Further functional analysis of the WAxR effectors in resistance and

672 susceptible host cultivars can elucidate their role as a potential effector or avirulence

673 candidates similar to the RxLR motif-containing effectors.

\section{Acknowledgments}

675 TRS is thankful to the Department of Science and Technology, Govt. of India, for JC 676 Bose National Fellowship. RJ is thankful to the University Grants Commission (UGC), 677 New Delhi for providing Junior Research Fellowship (JRF). 'The authors also gratefully 678 acknowledge Miss Aakriti Mehra for assistance in confocal imaging experiments. 679

\section{Conflict of Interests}

681 The authors declare no conflict of interests

682

\section{CRediT authorship contribution statement}

Conceptualization: Tilak Raj Sharma and Rajdeep Jaswal

Data curation and lab experiments: Rajdeep Jaswal

Data analysis and writing first draft: Rajdeep Jaswal, Sivasubramanian

687 Rajarammohan, Himanshu Dubey, Kanti Kiran, Hukam Rawal, Humira Sonah, Rupesh

688 Deshmukh, Naveen Gupta

689 Funding acquisition: Tilak Raj Sharma

690 Resource: Subhash C Bhardwaj and Pramod Prasad

691 Investigation: Rajdeep Jaswal

692 Methodology and writing final draft: Tilak Raj Sharma and Rajdeep Jaswal 


\section{References}

Able, A.J., 2003. Role of reactive oxygen species in the response of barley to necrotrophic pathogens. Protoplasma 221, 137-143.

Adams, T.M., Olsson, T.S.G., Ramírez-González, R.H., Bryant, R., Bryson, R., Campos, P.E., Fenwick, P., Feuerhelm, D., Hayes, C., Henriksson, T., 2021. Rust expression browser: an open-source database for simultaneous analysis of host and pathogen gene expression profiles with expVIP. BMC Genomics 22, 1-10.

Bailey, T.L., Boden, M., Buske, F.A., Frith, M., Grant, C.E., Clementi, L., Ren, J., Li, W.W., Noble, W.S., 2009. MEME SUITE: tools for motif discovery and searching. Nucleic Acids Res. 37, W202-W208.

Brameier, M., Krings, A., MacCallum, R.M., 2007. NucPred-predicting nuclear localization of proteins. Bioinformatics 23, 1159-1160.

Cortázar, A.R., Aransay, A.M., Alfaro, M., Oguiza, J.A., Lavín, J.L., 2014. SECRETOOL: integrated secretome analysis tool for fungi. Amino Acids 46, 471-473.

de Guillen, K., Lorrain, C., Tsan, P., Barthe, P., Petre, B., Saveleva, N., Rouhier, N., Duplessis, S., Padilla, A., Hecker, A., 2019. Structural genomics applied to the rust fungus Melampsora larici-populina reveals two candidate effector proteins adopting cystine knot and NTF2-like protein folds. Sci. Rep. 9, 1-12.

Deising, H., Siegrist, J., 1995. Chitin deacetylase activity of the rust Uromyces viciaefabae is controlled by fungal morphogenesis. FEMS Microbiol. Lett. 127, 207-211.

Dou, D., Kale, S.D., Wang, X., Jiang, R.H.Y., Bruce, N.A., Arredondo, F.D., Zhang, X., 
Tyler, B.M., 2008. RXLR-mediated entry of Phytophthora sojae effector Avr1b into soybean cells does not require pathogen-encoded machinery. Plant Cell 20, 19301947.

Dubey, M., Vélëz, H., Broberg, M., Jensen, D.F., Karlsson, M., 2020. LysM Proteins Regulate Fungal Development and Contribute to Hyphal Protection and Biocontrol Traits in Clonostachys rosea. Front. Microbiol.

Duplessis, S., Cuomo, C.A., Lin, Y.-C., Aerts, A., Tisserant, E., Veneault-Fourrey, C., Joly, D.L., Hacquard, S., Amselem, J., Cantarel, B.L., 2011. Obligate biotrophy features unraveled by the genomic analysis of rust fungi. Proc. Natl. Acad. Sci. 108, 9166-9171.

Godfrey, D., Böhlenius, H., Pedersen, C., Zhang, Z., Emmersen, J., Thordal-Christensen, H., 2010. Powdery mildew fungal effector candidates share N-terminal Y/F/WxCmotif. BMC Genomics 11, 317.

GONG, A., JING, Z., ZHANG, K., TAN, Q., WANG, G., LIU, W., 2020. Bioinformatic analysis and functional characterization of the cfem proteins in maize anthracnose fungus Colletotrichum graminicola. J. Integr. Agric. 19, 541-550.

Gruber, S., Seidl-Seiboth, V., 2012. Self versus non-self: fungal cell wall degradation in Trichoderma. Microbiology 158, 26-34.

Gu, B., Kale, S.D., Wang, Q., Wang, D., Pan, Q., Cao, H., Meng, Y., Kang, Z., Tyler, B.M., Shan, W., 2011. Rust secreted protein Ps87 is conserved in diverse fungal pathogens and contains a RXLR-like motif sufficient for translocation into plant cells. PLoS One 6, e27217. 
736

737

738

739

740

741

742

743

744

745

746

747

748

749

750

751

752

753

754

755

756

757

Gui, Y., Chen, J., Zhang, D., Li, N., Li, T., Zhang, W., Wang, X., Short, D.P.G., Li, L., Guo, W., 2017. Verticillium dahliae manipulates plant immunity by glycoside hydrolase 12 proteins in conjunction with carbohydrate $\square$ binding module 1 . Environ. Microbiol. 19, 1914-1932.

Guyon, K., Balagué, C., Roby, D., Raffaele, S., 2014. Secretome analysis reveals effector candidates associated with broad host range necrotrophy in the fungal plant pathogen Sclerotinia sclerotiorum. BMC Genomics 15, 336.

Jaswal, R., Dubey, H., Kiran, K., Singh, P.K., Rawal, H.C., Bhardwaj, S.C., Prasad, P., Gupta, N., Sharma, T.R., 2019. Comparative secretome analysis of Indian wheat leaf rust pathogen Puccinia triticina. Indian J. Agric. Sci. 89, 1688-1692.

Jaswal, R., Kiran, K., Rajarammohan, S., Dubey, H., Singh, P.K., Sharma, Y., Deshmukh, R., Sonah, H., Gupta, N., Sharma, T.R., 2020. Effector Biology of Biotrophic Plant Fungal Pathogens: Current Advances and Future Prospective. Microbiol. Res. 126567 .

Jones, D.A.B., Bertazzoni, S., Turo, C.J., Syme, R.A., Hane, J.K., 2018. Bioinformatic prediction of plant-pathogenicity effector proteins of fungi. Curr. Opin. Microbiol. $46,43-49$.

Jorda, J., Kajava, A. V, 2009. T-REKS: identification of Tandem REpeats in sequences with a K-meanS based algorithm. Bioinformatics 25, 2632-2638.

Kale, S.D., Gu, B., Capelluto, D.G.S., Dou, D., Feldman, E., Rumore, A., Arredondo, F.D., Hanlon, R., Fudal, I., Rouxel, T., 2010. External lipid PI3P mediates entry of eukaryotic pathogen effectors into plant and animal host cells. Cell 142, 284-295. 
Karnaouri, A., Topakas, E., Antonopoulou, I., Christakopoulos, P., 2014. Genomic insights into the fungal lignocellulolytic system of Myceliophthora thermophila. Front. Microbiol. 5 .

Kim, K.-T., Jeon, J., Choi, J., Cheong, K., Song, H., Choi, G., Kang, S., Lee, Y.-H., 2016. Kingdom-wide analysis of fungal small secreted proteins (SSPs) reveals their potential role in host association. Front. Plant Sci. 7.

Kim, S., Ahn, I., Rho, H., Lee, Y., 2005. MHP1, a Magnaporthe grisea hydrophobin gene, is required for fungal development and plant colonization. Mol. Microbiol. 57, $1224-1237$.

Kiran, K., Rawal, H.C., Dubey, H., Jaswal, R., Bhardwaj, S.C., Prasad, P., Pal, D., Devanna, B.N., Sharma, T.R., 2017. Dissection of genomic features and variations of three pathotypes of Puccinia striiformis through whole genome sequencing. Sci. Rep. 7.

Kiran, K., Rawal, H.C., Dubey, H., Jaswal, R., Devanna, B.N., Gupta, D.K., Bhardwaj, S.C., Prasad, P., Pal, D., Chhuneja, P., 2016. Draft genome of the wheat rust pathogen (Puccinia triticina) unravels genome-wide structural variations during evolution. Genome Biol. Evol. 8, 2702-2721.

Kombrink, A., Thomma, B.P.H.J., 2013. LysM effectors: secreted proteins supporting fungal life. PLoS Pathog. 9.

Kubicek, C.P., Starr, T.L., Glass, N.L., 2014. Plant cell wall-degrading enzymes and their secretion in plant-pathogenic fungi. Annu. Rev. Phytopathol. 52, 427-451. 
Kumar, S., Stecher, G., Tamura, K., 2016. MEGA7: Molecular Evolutionary Genetics Analysis version 7.o for bigger datasets. Mol. Biol. Evol. msw054.

Levin, E., Ballester, A.R., Raphael, G., Feigenberg, O., Liu, Y., Norelli, J., GonzalezCandelas, L., Ma, J., Dardick, C., Wisniewski, M., 2017. Identification and characterization of LysM effectors in Penicillium expansum. PLoS One 12.

Librado, P., Rozas, J., 2009. DnaSP v5: a software for comprehensive analysis of DNA polymorphism data. Bioinformatics 25, 1451-1452.

Liu, J., Guan, T., Zheng, P., Chen, L., Yang, Y., Huai, B., Li, D., Chang, Q., Huang, L., Kang, Z., 2016. An extracellular Zn $\square$ only superoxide dismutase from Puccinia strïformis confers enhanced resistance to host $\square$ derived oxidative stress. Environ. Microbiol. 18, 4118-4135.

Liu, L., Xu, L., Jia, Q., Pan, R., Oelmüller, R., Zhang, W., Wu, C., 2019. Arms race: diverse effector proteins with conserved motifs. Plant Signal. Behav. 14, 1557008.

Lowe, R.G.T., Howlett, B.J., 2012. Indifferent, affectionate, or deceitful: lifestyles and secretomes of fungi. PLoS Pathog. 8, e1002515.

Lu, S., Wang, J., Chitsaz, F., Derbyshire, M.K., Geer, R.C., Gonzales, N.R., Gwadz, M., Hurwitz, D.I., Marchler, G.H., Song, J.S., 2020. CDD/SPARCLE: the conserved domain database in 2020. Nucleic Acids Res. 48, D265-D268.

Ma, L.-J., Van Der Does, H.C., Borkovich, K.A., Coleman, J.J., Daboussi, M.-J., Di Pietro, A., Dufresne, M., Freitag, M., Grabherr, M., Henrissat, B., 2010. Comparative genomics reveals mobile pathogenicity chromosomes in Fusarium. 
Nature 464, 367-373.

Ma, Z., Song, T., Zhu, L., Ye, W., Wang, Y., Shao, Y., Dong, S., Zhang, Z., Dou, D., Zheng, X., 2015. A Phytophthora sojae glycoside hydrolase 12 protein is a major virulence factor during soybean infection and is recognized as a PAMP. Plant Cell 27, 20572072.

Marchler-Bauer, A., Bryant, S.H., 2004. CD-Search: protein domain annotations on the fly. Nucleic Acids Res. 32, W327-W331.

Mayer, A.M., Staples, R.C., Gil-ad, N.L., 2001. Mechanisms of survival of necrotrophic fungal plant pathogens in hosts expressing the hypersensitive response. Phytochemistry 58, 33-41.

Mesarich, C.H., Bowen, J.K., Hamiaux, C., Templeton, M.D., 2015. Repeat-containing protein effectors of plant-associated organisms. Front. Plant Sci. 6.

Mukhi, N., Gorenkin, D., Banfield, M.J., 2020. Exploring folds, evolution and host interactions: understanding effector structure/function in disease and immunity. New Phytol. n/a. https://doi.org/10.1111/nph.16563

Newman, A.M., Cooper, J.B., 2007. XSTREAM: a practical algorithm for identification and architecture modeling of tandem repeats in protein sequences. BMC Bioinformatics 8, 382 .

Orts, F., Ten Have, A., 2018. Structure-function analysis of Sedolisins: evolution of tripeptidyl peptidase and endopeptidase subfamilies in fungi. BMC Bioinformatics $19,1-15$. 
821

822

823

824

825

826

827

828

829

830

831

832

833

834

835

836

837

838

839

840

841

Ozketen, A.C., Andac, A., Dagvadorj, B., Demiralay, B., Akkaya, M.S., 2020. In-depth secretome analysis of Puccinia striiformis $f$. sp. tritici in infected wheat uncovers effector functions. bioRxiv.

Palomares-Rius, J.E., Hirooka, Y., Tsai, I.J., Masuya, H., Hino, A., Kanzaki, N., Jones, J.T., Kikuchi, T., 2014. Distribution and evolution of glycoside hydrolase family 45 cellulases in nematodes and fungi. BMC Evol. Biol. 14, 69.

Paris, S., Debeaupuis, J.-P., Crameri, R., Carey, M., Charlès, F., Prévost, M.C., Schmitt, C., Philippe, B., Latgé, J.P., 2003. Conidial hydrophobins of Aspergillus fumigatus. Appl. Environ. Microbiol. 69, 1581-1588.

Petre, B., Kamoun, S., 2014. How do filamentous pathogens deliver effector proteins into plant cells? PLoS Biol 12, e1001801.

Rajarammohan, S., 2021. Redefining Plant-Necrotroph Interactions: The Thin Line Between Hemibiotrophs and Necrotrophs. Front. Microbiol. 12, 944.

Rastogi, S., Cygan, A.M., Boothroyd, J.C., 2019. Translocation of effector proteins into host cells by Toxoplasma gondii. Curr. Opin. Microbiol. 52, 130-138.

Reichard, U., Léchenne, B., Asif, A.R., Streit, F., Grouzmann, E., Jousson, O., Monod, M., 2006. Sedolisins, a new class of secreted proteases from Aspergillus fumigatus with endoprotease or tripeptidyl-peptidase activity at acidic pHs. Appl. Environ. Microbiol. 72, 1739.

Saunders, D.G.O., Win, J., Cano, L.M., Szabo, L.J., Kamoun, S., Raffaele, S., 2012. Using hierarchical clustering of secreted protein families to classify and rank candidate 
effectors of rust fungi. PLoS One 7, e29847.

843

844

845

846

847

848

849

850

851

852

853

854

855

856

857

858

859

860

861

862

Sevim, A., Donzelli, B.G.G., Wu, D., Demirbag, Z., Gibson, D.M., Turgeon, B.G., 2012. Hydrophobin genes of the entomopathogenic fungus, Metarhizium brunneum, are differentially expressed and corresponding mutants are decreased in virulence. Curr. Genet. 58, 79-92.

Sonah, H., Deshmukh, R.K., Bélanger, R.R., 2016. Computational prediction of effector proteins in fungi: opportunities and challenges. Front. Plant Sci. 7.

Sperschneider, J., Catanzariti, A.-M., DeBoer, K., Petre, B., Gardiner, D.M., Singh, K.B., Dodds, P.N., Taylor, J.M., 2017. LOCALIZER: subcellular localization prediction of both plant and effector proteins in the plant cell. Sci. Rep. 7 .

Sperschneider, J., Dodds, P.N., Gardiner, D.M., Singh, K.B., Taylor, J.M., 2018.

Improved prediction of fungal effector proteins from secretomes with EffectorP 2.0. Mol. Plant Pathol. 19, 2094-2110.

Sperschneider, J., Gardiner, D.M., Dodds, P.N., Tini, F., Covarelli, L., Singh, K.B., Manners, J.M., Taylor, J.M., 2016. EffectorP: predicting fungal effector proteins from secretomes using machine learning. New Phytol. 210, 743-761.

Sperschneider, J., Gardiner, D.M., Taylor, J.M., Hane, J.K., Singh, K.B., Manners, J.M., 2013. A comparative hidden Markov model analysis pipeline identifies proteins characteristic of cereal-infecting fungi. BMC Genomics 14, 807.

Tenhaken, R., Levine, A., Brisson, L.F., Dixon, R.A., Lamb, C., 1995. Function of the oxidative burst in hypersensitive disease resistance. Proc. Natl. Acad. Sci. 92, 4158- 
4163.

864

865

866

867

868

869

870

871

872

873

874

875

876

877

878

879

880

881

882

883

Torres, M.A., Jones, J.D.G., Dangl, J.L., 2006. Reactive oxygen species signaling in response to pathogens. Plant Physiol. 141, 373-378.

Wang, S., Vetukuri, R.R., Kushwaha, S.K., Hedley, P.E., Morris, J., Studholme, D.J., Welsh, L.R.J., Boevink, P.C., Birch, P.R.J., Whisson, S.C., 2021. Haustorium formation and a distinct biotrophic transcriptome characterize infection of Nicotiana benthamiana by the tree pathogen Phytophthora kernoviae. Mol. Plant Pathol.

Wang, Y., Coleman-Derr, D., Chen, G., Gu, Y.Q., 2015. OrthoVenn: a web server for genome wide comparison and annotation of orthologous clusters across multiple species. Nucleic Acids Res. 43, W78-W84.

Whisson, S.C., Boevink, P.C., Moleleki, L., Avrova, A.O., Morales, J.G., Gilroy, E.M., Armstrong, M.R., Grouffaud, S., Van West, P., Chapman, S., 2007. A translocation signal for delivery of oomycete effector proteins into host plant cells. Nature 450, $115-118$.

Winnenburg, R., Baldwin, T.K., Urban, M., Rawlings, C., Köhler, J., Hammond-Kosack, K.E., 2006. PHI-base: a new database for pathogen host interactions. Nucleic Acids Res. 34, D459-D464.

Xu, Q., Tang, C., Wang, L., Zhao, C., Kang, Z., Wang, X., 2020. Haustoria - arsenals during the interaction between wheat and Puccinia striiformis f. sp. tritici. Mol. Plant Pathol. 21, 83-94. https://doi.org/10.1111/mpp.12882 
884

885

886

887

888

889

890

891

892

893

894

895

896

897

898

899

900

901

902

Xu, Q., Tang, C., Wang, Xiaodong, Sun, S., Zhao, J., Kang, Z., Wang, Xiaojie, 2019. An effector protein of the wheat stripe rust fungus targets chloroplasts and suppresses chloroplast function. Nat. Commun. 10, 1-13.

Yang, J., Yan, R., Roy, A., Xu, D., Poisson, J., Zhang, Y., 2015. The I-TASSER Suite: protein structure and function prediction. Nat. Methods 12, 7-8.

Yin, C., Ramachandran, S.R., Zhai, Y., Bu, C., Pappu, H.R., Hulbert, S.H., 2019. A novel fungal effector from Puccinia graminis suppressing RNA silencing and plant defense responses. New Phytol.

Yin, Y., Mao, X., Yang, J., Chen, X., Mao, F., Xu, Y., 2012. dbCAN: a web resource for automated carbohydrate-active enzyme annotation. Nucleic Acids Res. 40, W445W451.

Zhao, S., Shang, X., Bi, W., Yu, X., Liu, D., Kang, Z., Wang, Xiaojie, Wang, Xiaodong, 2020. Genome-Wide Identification of Effector Candidates With Conserved Motifs From the Wheat Leaf Rust Fungus Puccinia triticina . Front. Microbiol. .

Zhu, W., Wei, W., Wu, Y., Zhou, Y., Peng, F., Zhang, S., Chen, P., Xu, X., 2017. BcCFEM1, a CFEM Domain-Containing Protein with Putative GPI-Anchored Site, Is Involved in Pathogenicity, Conidial Production, and Stress Tolerance in Botrytis cinerea. Front. Microbiol. 8, 1807. 